\title{
Effects of fuel and forest conservation on future levels of atmospheric carbon dioxide
}

\author{
James C.G. Walker a and James F. Kasting ${ }^{\mathrm{b}}$ \\ "Department of Atmospheric, Oceanic, and Space Sciences, Unicersity of Michigan, Ann Arbor, MI 48109, USA \\ "Department of Geosciences, The Pennsyliania State Unicersity, Unicersity Park, PA 10802, USA
}

(Received December 12, 1990; revised and accepted May 23, 1990)

\begin{abstract}
Walker, J.C.G. and Kasting, J.F., 1991. Effects of fuel and forest conservation on future levels of atmospheric carbon dioxide. Palaeogeogr., Palaeoclimatol., Palaeoecol. (Global Planet. Change Sect.), 97: 151-189.
\end{abstract}

We develop a numerical simulation of the global biogeochemical cycles of carbon that works over time scales extending from years to millions of years. The ocean is represented by warm and cold shallow water reservoirs, a thermocline reservoir, and deep Atlantic, Indian, and Pacific reservoirs. The atmosphere is characterized by a single carbon reservoir and the glohal biota by a single biomass reservoir. The simulation includes the rock cycle, distinguishing between shelf carbonate and pelagic carbonate precipitation, with distinct lysocline depths in the three deep ocean reservoirs. Dissolution of pelagic carbonates in response to decrease in lysocline depth is included.

The simulation is tuned to reproduce the observed radiocarbon record resulting from atomic weapon testing. It is tuned also to reproduce the distribution of dissolved phosphate and total dissolved carbon between the ocean reservoirs as well as the carbon isotope ratios for both ${ }^{13} \mathrm{C}$ and ${ }^{14} \mathrm{C}$ in ocean and atmosphere. The simulation reproduces reasonably well the historical record of carbon dioxide partial pressure as well as the atmospheric isotope ratios for ${ }^{13} \mathrm{C}$ and ${ }^{14} \mathrm{C}$ over the last $200 \mathrm{yr}$ as these have changed in response to fossil fuel burning and land use changes, principally forest clearance. The agreements between observation and calculation involves the assumption of a carbon dioxide fertilization effect in which the rate of production of biomass increases with increasing carbon dioxide partial pressure. At present the fertilization effect of increased carbon dioxide outweighs the effects of forest clearance, so the biota comprises an overall sink of atmosph ric carbon dioxide sufficiently large to bring the budget approximately into balance.

This simulation is used to examine the future evolution of carbon dioxide and its sensitivity to assumptions about the rate of fossil fuel burning and of forest clearance. Over times extending up to thousands of years, the results are insensitive to the formulation of the rock cycle and to the dissolution of deep sea carbonate sediments. Atmospheric carbon dioxide continues to increase as long fossil fuel is burned at a significant rate, because the rate of fossil fuel production of carbon dioxide far exceeds the rates at which geochemical processes can remove carbon dioxide from the atmosphere. The maximum concentration of carbon dioxide achieved in the atmosphere depends on the total amount of fossil fuel burned, but only weakly on the rate of burning. The future course of atmospheric carbon dioxide is, however, very sensitive to the fate of the forests in this simulation because of the important role assigned to carbon dioxide fertilization of plant growth rate. Forest clearance drives up atmospheric carbon dioxide not only by converting biomass into atmospheric carbon dioxide but more importantly by reducing the capacity of the biota to sequester fossil fuel carbon dioxide. In this simulation, atmospheric carbon dioxide levels could be sustained indefinitely below 500 parts per million (ppm) if fossil fuel combustion rates were immediately cut from their present value of $5 \times 10^{14} \mathrm{~m} / \mathrm{y}$ to $0.2 \times 10^{14} \mathrm{~m} / \mathrm{y}$ (a factor of 25 reduction) and if further forest clearance were halted. If neither of these conditions is met and if we consume most of the world's fossil fuel reserves, peak carbon dioxide concentrations of 1000-2000 ppm are probable within the next few centuries.

\section{Introduction and overview}

Correspondence to: J.F. Kasting, Department of Geosciences, The Pennsylvania State University, University Park, PA 16802 , USA
It is by now widely recognized that man has the capability of warming Earth's climate by caus- 
ing a buildup of greenhouse gases in the atmosphere. The principal culprit is carbon dioxide released by the burning of fossil fuels and by changes in land use patterns, especially deforestation. Other trace gases (methane, nitrous oxide, freons) are also contributing to the increase in the greenhouse effect, but none of these gases has the same long lifetime as $\mathrm{CO}_{2}$ and, hence, the same capability of producing long-lasting climatic change. In this paper we consider how $\mathrm{CO}_{2}$ and climate may vary on time scales of hundreds to hundreds of thousands of years in response to man's activities.

\section{I Precious studies (brief summary)}

Projections of how atmospheric $\mathrm{CO}_{2}$ may vary during the next few centuries in response to fossil fuel burning have made by several different investigators (Keeling and Bacastrow, 1977; Revelle and Munk, 1977; Bolin et al., 1979; Bacastrow and Bjorkstrom, 1981; Broecker and Peng, 1982; Sundquist, 1986). The greatest uncertainty in any such calculation is the future rate of burning and the total amount of fossil fuel that will eventually be consumed. A typical assumption is that the burning rate will increase from its present value of $5 \times 10^{14}$ moles $\mathrm{C} \mathrm{yr}{ }^{-1}$ (Rotty and Marland, 1986), henceforth abbreviated as $5 \times 10^{14} \mathrm{~m} / \mathrm{y}$ to four or five times that value by the year 2100 and then decline to nearly zero over the next $300 \mathrm{yr}$ as the fossil fuel reserves are exhausted (Fig. 1a). The total amount of recoverable fossil fuels (most of which is coal) is considered to be in the range of 4000 to 6000 Gtons carbon, or $(3.5-5.0) \times 10^{17}$ moles C (Bacastrow and Bjorkstrom, 1981; Broecker and Peng, 1982). This is 7-10 times the amount of carbon dioxide that was present in the atmosphere prior to the onset of the industrial age, when the $\mathrm{CO}_{2}$ concentration was about 280 ppm (Neftel et al., 1985).

Most carbon cycle modelers, including us, assume that the principal sink for carbon dioxide during the next few centuries will be the ocean. The rate at which the ocean can take up $\mathrm{CO}_{2}$ is estimated by determining how fast it absorbs tracers such as ${ }^{14} \mathrm{C}$ and tritium. By combining an ocean uptake model with a postulated fossil fuel

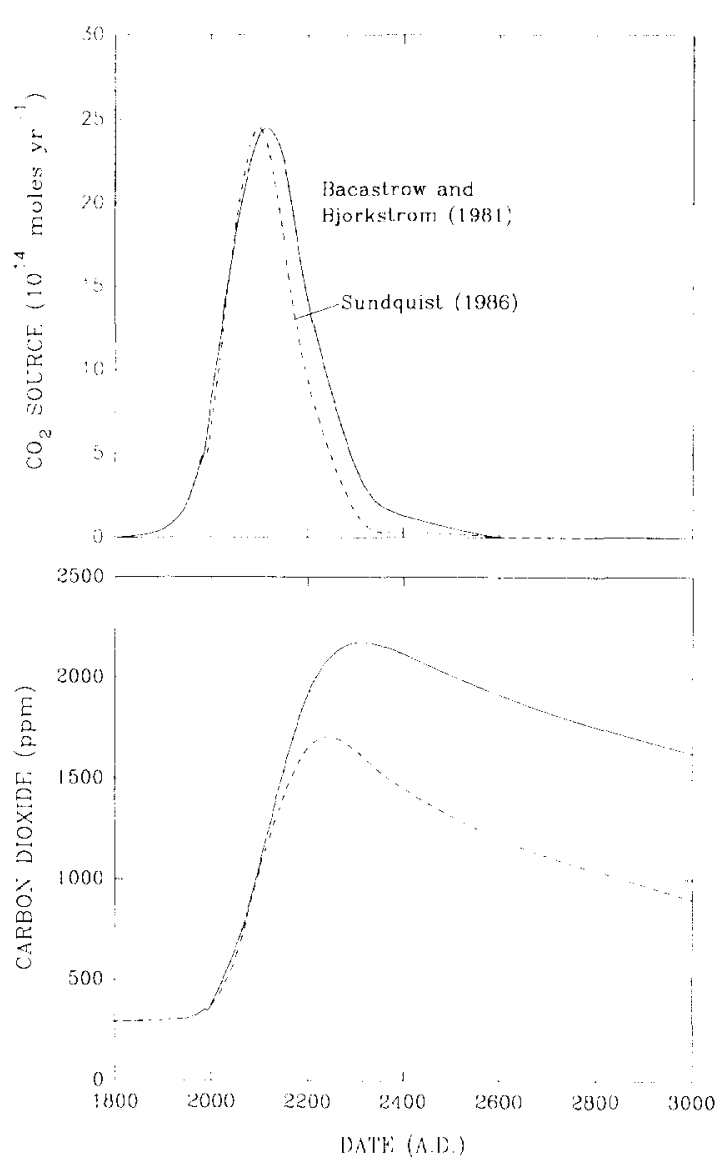

Fig. 1. Assumed fossil burning rates (top) and calculated atmospheric $\mathrm{CO}_{2}$ concentrations (bottom) in two previous models of the global carbon cycle. The total amount of fossil fuel consumed in $5 \times 10^{17}$ moles $\mathrm{C}$ for Bacastrow and Bjorkstrom (1981) and $4.2 \times 10^{17}$ moles $C$ for Sundquist (1986). The Bacastrow and Bjorkstrom calculation is their "slow burning" case $(n=0.25)$.

burning scenario, one can estimate how atmospheric $\mathrm{CO}_{2}$ concentrations will vary during the next few centuries. The results of two such model calculations are shown in Fig. 1b. The models predict a five- to seven-fold increase in atmospheric $\mathrm{CO}_{2}$ levels over the next $300 \mathrm{yr}$, followed by a long, slow decline. Of the two calculations shown here, Sundquist predicts a smaller increase and a faster decline because he assumes a smaller net consumption of fossil fuels (5000 Gtons C versus 6156 Gtons $C$ ) and because he includes dissolution of seafloor carbonates. More will be said about this in the next section. For the present, we simply note that the predictions of these models are roughly comparable, as are our own 
predictions when we make similar assumptions (Section 5).

\subsection{This study}

Our model differs from the two shown in Fig. 1 in three main respects. First, it includes a simple, and admittedly speculative, representation of the exchange of carbon between the atmosphere, forests, and soils. This terrestrial carbon cycle is needed to allow the model to reproduce the past histories of atmospheric $\mathrm{CO}_{2}$ and atmospheric and oceanic carbon isotopes. It also allows us to bound the extent to which the terrestrial biota may influence future atmospheric $\mathrm{CO}_{2}$ levels. Second, we also include the long term carbonate-silicate cycle, in which carbon is exchanged between the atmosphere/ocean system and carbonate rocks. This allows us to carry our computations into the distant future and to calculate how long it will take for the atmospheric $\mathrm{CO}_{2}$ concentration to decay to its original preindustrial value. No previous model of fossil fuel $\mathrm{CO}_{2}$ uptake has done this explicitly, although Sundquist (1986) has discussed the problem qualitatively. Finally, we consider a wider range of burning scenarios than has been looked at in most studies. In particular, we examine the extent to which future atmospheric $\mathrm{CO}_{2}$ levels could be reduced by implementing strict energy conservation measures in the immediate future. We do this by performing simulations in which the recoverable fossil fuels are consumed at much slower rates than those shown in Fig. 1.

We begin with a general review of the global carbon cycle in which we explore the carbon reservoirs and the processes most likely to influence atmospheric carbon dioxide on a time scale of decades to millennia. This review guides the development of the mathematical model, which is presented in Section 2. We have sought to keep our model as simple as possible, consistent with a plausible representation of the most important processes, so that underlying realities shall not be obscured by computational complexities. The fluxes of water and biogenic particles included in the oceanic component of the model are tuned to reproduce observed values of carbon isotope ra-

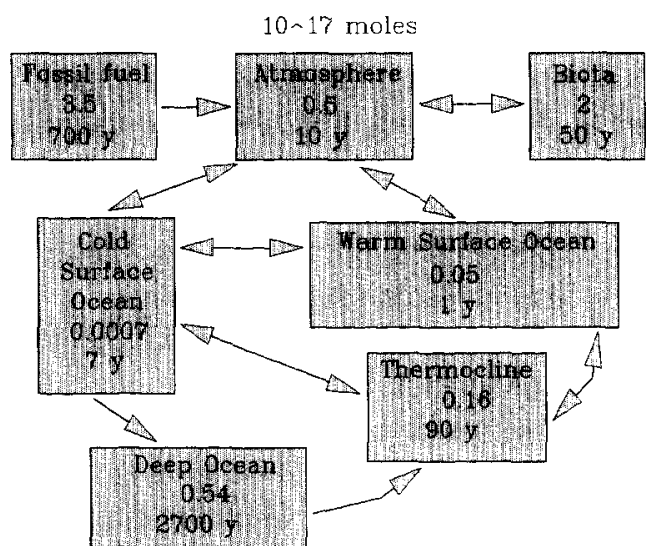

Fig. 2. Various reservoirs that affect atmospheric carbon dioxide. Reservoir capacities are quoted in units of $10^{17}$ moles. The capacities of oceanic reservoirs are given by the carbonate ion concentration, $\left[\mathrm{CO}_{3}^{2}-\right]$, not the total dissolved carbon concentration. because absorption of carbon dioxide without change in alkalinity converts carbonate ions to bicarbonate ions. The times associated with the oceanic reservoirs are the times to respond to a change in atmospheric carbon dioxide. For fossil fuel, atmosphere, and biota reservoirs, the times are the carbon residence times at current rates of exchange.

tios, nutrient concentrations, and total dissolved carbon. The predictive capabilities of the model are then tested against the observed record of atmospheric carbon dioxide and the carbon isotopes using the history of release of fossil fuel carbon dioxide and the history of land use changes affecting biomass. Our results show reasonable agreement both with the present distribution of tracers in the sea and with the history of carbon dioxide and its isotopes. However, our model is a very simple representation of the real world and incorporates a number of quite arbitrary assumptions. The agreement between calculation and observation does not necessarily mean that the calculations are correct, therefore. All we can say at this point is that the model is not obviously wrong.

\subsection{Constraints on carbon exchange}

The carbon dioxide content of the atmosphere is affected by release of carbon dioxide in the burning of fossil fuels, exchange with the biota, and exchange with the ocean. Figure 2 shows the carbon exchange rates and the carbon absorption capacities of the reservoirs that are most impor- 
tant on the short time scale. The present rate of fossil fuel burning is large enough to double the carbon dioxide content of the atmosphere in a time of about $100 \mathrm{yr}$. At the present rate of burning it would take $700 \mathrm{yr}$ to exhaust the estimated reserve of recoverable fossil fuel. The large reservoir of organic carbon as biomass includes soil organic carbon, but not dissolved organic carbon in sea water. Exchange between the atmosphere and this large biomass reservoir is rapid.

Because of the constraints of charge balance, the capacity of the ocean to absorb carbon dioxide is limited. As long as carbon dioxide is the only constituent being exchanged with the ocean the dissolution reaction is, in effect

$\mathrm{CO}_{3}^{2--}+\mathrm{H}_{2} \mathrm{O}+\mathrm{CO}_{2} \rightarrow 2 \mathrm{HCO}_{3}^{-}$

The capacity of sea water to absorb carbon dioxide is therefore limited by the concentration of dissolved carbonate ions, a concentration only one-tenth as large as the concentration of total dissolved carbon. The absorption capacities of the oceanic reservoirs in Fig. 2 are calculated by multiplying the reservoir volume by the corresponding concentration of carbonate ions. The surface ocean reservoirs exchange carbon rapidly with the atmosphere, but their capacities are too small for them to exert a controlling influence on atmospheric carbon dioxide. Because of its much larger volume, the capacity of the deep ocean reservoir is significant, but the time scale associated with carbon transfer into the deep ocean is $1000 \mathrm{yr}$ or more, so the behavior of atmospheric carbon dioxide on a time scale of decades to centuries is little affected by exchange with the deep ocean. It is for this reason that it is not necessary to describe the ocean circulation in great detail in order to predict atmospheric concentrations of carbon dioxide over times of decades to centuries. The oceanic reservoirs that exchange rapidly with the atmosphere are small; the large, deep ocean reservoir exchanges slowly with the atmosphere.

The deep ocean reservoirs are shown in more detail in Fig. 3. Deep sea water ages as it moves from the Atlantic to the Indian to the Pacific Ocean because deep water forms principally in the Atlantic. The times in Figs. 2 and 3 are the

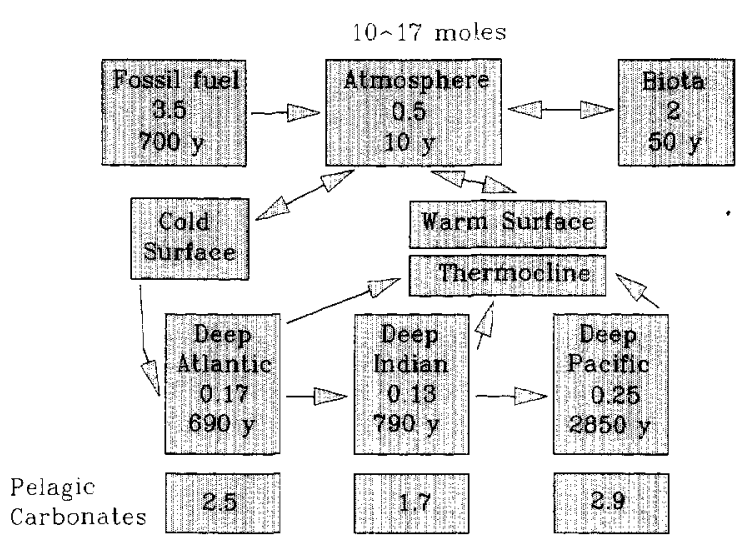

Fig. 3. The carbon capacity of various surface reservoirs, with more detailed description of the deep ocean. The ability of the deep ocean reservoirs to absorb carbon dioxide is greatly enhanced by the dissolution of pelagic carbonates. The indicated reservoir capacities correspond to the carbonate content in the $10 \mathrm{p} 30 \mathrm{~cm}$ of pelagic sediments integrated over the area of the sea floor above the lysocline.

times to respond to an atmospheric perturbation. Because of the pressure and temperature dependence of the solubility of calcium carbonate, the deepest portions of the oceans are undersaturated with respect to calcium carbonate while the shallower portions are supersaturated. Addition of carbon dioxide to the deep ocean renders the waters more corrosive, making possible the dissolution of deep sea pelagic carbonate sediments. Carbonate dissolution affects the charge balance in such a way as to permit more carbon dioxide to dissolve. The effective reaction is

$\mathrm{CaCO}_{3}+\mathrm{H}_{2} \mathrm{O}+\mathrm{CO}_{2} \rightarrow \mathrm{Ca}^{2+}+2 \mathrm{HCO}_{3}^{-}$

The capacity of the deep ocean reservoirs to absorb carbon dioxide is therefore very significantly affected by the dissolution of pelagic carbonates. Figure 3 shows an estimate of the carbon absorption capacity associated with the dissolution of pelagic carbonates. The values have been calculated to include the carbonate minerals in the top $30 \mathrm{~cm}$ of pelagic sediments, 6000 moles $/ \mathrm{m}^{2}$, over the area of sea floor above the lysocline (Broecker and Peng, 1982). With allowance for the dissolution of pelagic carbonates, the capacity of deep sea water to absorb carbon dioxide is large, but this process still does not begin to affect the atmosphere on a time scale shorter than the ventilation time of the deep sea, 
about $1000 \mathrm{yr}$. The dissolution of shallow water carbonates is not expected to occur because shallow waters are strongly supersaturated with respect to carbonate minerals. The dissolution of terrestrial carbonate deposits in weathering reactions contributes a flux of calcium and dissolved carbon carried to the oceans by rivers that is much smaller than any of the fluxes in Figs. 2 and 3.

On a time scale of decades to centuries, atmospheric carbon dioxide is affected by rapid release from the relatively large fossil fuel reserve, rapid exchange with a large reservoir of terrestrial biomass, and rapid exchange with surface ocean reservoirs with little capacity to absorb carbon dioxide. Exchange with the large deep sea reservoir, for which the absorption capacity is enhanced by the solution of pelagic carbonates, takes millennia.

\section{Model development}

\subsection{Reservoirs}

For computational purposes the surface environment is partitioned into a small number of homogeneous reservoirs. The simulation calculates the evolution of the carbon content of each of these reservoirs in response to specified car-

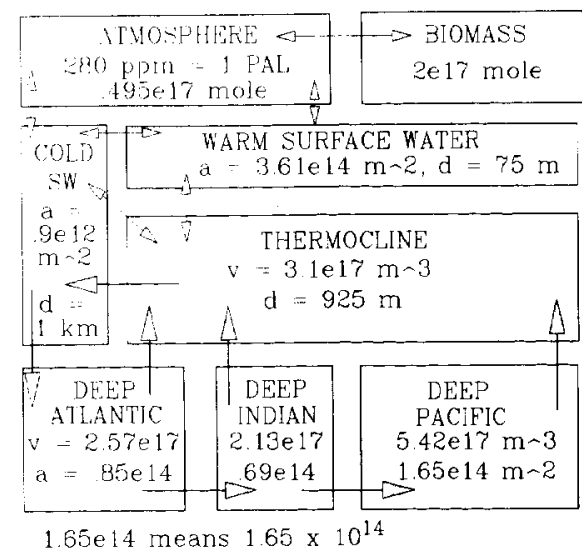

Fig. 4. Dimensions of the carbon reservoirs included in the numerical simulation. The areas of oceanic reservoirs are denoted by $a$, their vertical dimensions by $d$, and their volumes by $\because$. . Exchange processes are indicated by doubledheaded arrows and advective processes are indicated by single-headed arrows. bon sources and sinks and the exchange of material between reservoirs. The reservoirs and their interconnections are shown in Fig. 4. The atmosphere exchanges carbon with the biomass reservoir, with warm surface water, and with cold surface water. The pre-industrial concentration of carbon dioxide in the atmosphere was 280 parts per million (Neftel et al., 1985; Friedli et al., 1986), which is defined as 1 PAL (present atmospheric level), equal to an amount of 0.495 $\times 10^{17}$ moles of carbon dioxide. The carbon content of the biomass reservoir is taken initially to be $2 \times 10^{17}$ moles, of which $1.25 \times 10^{17}$ moles is in the form of soil humus (Schlesinger, 1986) and $0.75 \times 10^{17}$ moles is living biomass and litter (Woodwell et al., 1983; Esser, 1987). The division of the ocean into separate reservoirs is based largely on Broecker and Peng (1982), with volumes and areas from Menard and Smith (1966). The warm surface water reservoir has an area of $3.61 \times 10^{14} \mathrm{~m}^{2}$ and a thickness of $75 \mathrm{~m}$. The cold surface water reservoir has an area of only 0.009 $\times 10^{14} \mathrm{~m}^{2}$ and a thickness of $1 \mathrm{~km}$. This area has no geographical significance. Its value is a tuning parameter that affects both the carbon cycle and the global temperature distribution. Both of these surface water reservoirs exchange water with the thermocline in mixing processes. The thermocline has a volume of $3.1 \times 10^{17} \mathrm{~m}^{3}$ and a thickness of $925 \mathrm{~m}$. The mixing processes in the ocean denoted by double-headed arrows are ones in which the fluxes of water in each direction are equal. In addition to mixing with the thermocline water is exchanged between the surface reservoirs in a mixing process.

Circulation through the deep ocean is represented not as a mixing process but as advection, in which the flow is in one direction only. These flows are designated by the large single-headed arrows in the figure. Water flows from the cold surface water reservoir into the deep Atlantic and from there partly into the deep Indian reservoir and partly into the thermocline reservoir. There is an upwelling flux from the deep Indian reservoir into the thermocline and a flow also on into the deep Pacific reservoir. The thermohaline circulation is closed by upwelling from the deep Pacific into the thermocline reservoir and by a 
flow from the thermocline reservoir back into the cold surface water reservoir (Gordon, 1986). The volumes and areas of the deep ocean reservoirs are designated by $u$ and $a$. The upwelling velocity is assumed to be the same in each ocean basin, so the flux from deep ocean to thermocline is proportional to the area of the deep ocean reservoir. The other fluxes are calculated to conserve water. A better representation of the thermohaline circulation would include a second source of bottom water flowing directly into each ocean basin (Broecker and Peng, 1982, p. 371).

The choice of how to partition the surface environment into a small number of homogeneous reservoirs is to some extent arbitrary. The trick is to develop a system that can reasonably simulate the real world while maintaining computational and conceptual simplicity. In the rest of this paper we will not change the volumes of the oceanic reservoirs or the nature of the exchange processes, whether mixing or advective. The exchange coefficients and fluxes will be tuned so that the simulation reproduces various observed properties of the system, in a manner described in Section 3.

\subsection{Species and processes}

The simulation incorporates the rock cycle, but the processes of weathering and precipitation of chemical sediments occur too slowly to have significant impact on the short-term response of the ocean-atmosphere system. We shall therefore postpone discussion of the parameters of the rock cycle until later in the paper, describing first the processes that influence the short-term response.

\subsubsection{Phosphorus and photosynthesis}

Dissolved phosphorus is added to and removed from the ocean through the warm surface reservoir only. Addition is by rivers and removal is by incorporation into organic matter deposited in shelf sediments (Holland, 1978). the removal rate is assumed to be proportional to biological productivity in warm surface water which is in turn assumed to be proportional to the dissolved phosphorus concentration, so these interactions effectively fix the concentration of dissolved phosphorus in warm surface water. Dissolved phosphorus is transported from one oceanic reservoir to another by the thermohaline circulation and by the mixing processes already described. In addition, phosphorus is transported downwards from the warm surface water reservoir into the underlying thermocline and deep ocean reservoirs as a constituent of particulate organic matter produced by plankton. We neglect the transport of phosphorus associated with nonrefractory dissolved organic matter.

We calculate the downward flux of particulate organic matter, loosely described as productivity, by assuming that the phosphorus budget of the warm surface water reservoir is in instantaneous balance and that the concentration of dissolved phosphorus in this reservoir is a fixed fraction of the dissolved phosphorus concentration in the deep Pacific reservoir. This fraction, designated $f_{\mathrm{PD}}$, we take equal to 0.04 . Then, with all of the water fluxes specified, the amount by which the flow of dissolved phosphorus into the warm surface water reservoir exceeds the flow of dissolved phosphorus out of this reservoir is readily calculated. The difference is equal to the flux out of the reservoir in the form of particulate organic matter. The parameters have been set so that the concentration of dissolved phosphorus in river water is 1 millimole $/ \mathrm{m}^{3}$, the concentration in warm surface water is 0.1 millimole $/ \mathrm{m}^{3}$, and the concentration in deep Pacific water is 2.5 millimole $/ \mathrm{m}^{3}$ (Broecker and Peng, 1982, p. 309). The concentrations in the other reservoirs depend on the biogeochemical circulation of the ocean. Other formulations can be imagined for the relationship between productivity and phosphate circulation (Volk, 1989a). In this simulation, productivity is constant in time and space, so the formulation makes no difference to the results. Biological production in the cold surface water reservoir is neglected because this reservoir has small area and large depth.

Some of the particulate phosphorus is converted back into dissolved form in the thermocline reservoir; the rest settles into the underlying deep ocean reservoirs, at rates proportional to the areas of these reservoirs. We assume a constant value for the fraction of phosphorus re- 
TABLE 1

Selected model parameters

\begin{tabular}{lll}
\hline Parameter & Code name & Value \\
\hline$R_{\mathrm{CP}}$ & CTPR & 120 \\
$R_{\mathrm{CO}}$ & CORAT & 0.09 \\
$f_{\mathrm{PT}}$ & TCPFRAC & 0.925 \\
$f_{\mathrm{PD}}$ & PFP & 0.04 \\
$z_{1}$ & LYCON 1 & $5.8 \mathrm{~km}$ \\
$z_{2}$ & LYCON2 & $50 \mathrm{~km} /(\mathrm{mmol} / 1)$ \\
$\tau_{\mathrm{OA}}$ & DISTIME & $10 \mathrm{years}$ \\
$C_{\mathrm{Bio}}$ & BIOMZ & $2 \times 10^{17}$ moles \\
$M_{\mathrm{atm}}$ & MATMCO2 & $4.95 \times 10^{1 \mathrm{t}}$ moles \\
\hline
\end{tabular}

turned to dissolved form in the thermocline, a constant designated $f_{\mathrm{PT}}$. For simplicity, we assume that all particulate organic matter settling into the deep ocean reservoirs is converted back into dissolved form in these reservoirs, releasing dissolved phosphorus and total dissolved carbon. We ignore the small fraction of the particulate flux that is preserved to become a constituent of pelagic sediments.

Some of the particulate phosphorus is converted back into dissolved form in the thermocline reservoir; the rest settles into the underlying deep ocean reservoirs, at rates proportional to the areas of these reservoirs. We assume a constant value for the fraction of phosphorus returned to dissolved form in the thermocline, a constant designated $f_{\mathrm{PT}}$. For simplicity, we assume that all particulate organic settling into the deep ocean reservoirs is converted back into dissolved form in these reservoirs, releasing dissolved phosphorus and total dissolved carbon. We ignore the small fraction of the particulate flux that is preserved to become a constituent of pelagic sediments.

\subsubsection{Carbon}

Carbon dioxide is added to the atmosphere by volcanic and metamorphic processes at a rate that is held constant in this simulation. Additional sources of atmospheric carbon dioxide are the burning of fossil fuel, changes in the terrestrial biomass, and the oxidative weathering of sedimentary organic carbon. Carbon dioxide is removed from the atmosphere by exchange with the terrestrial biomass and by dissolution in cold warm surface water reservoirs. The carbon dioxide flux between ocean and atmosphere is proportional to the area of the surface water reservoir and to the difference between the partial pressure of carbon dioxide in the atmosphere and the partial pressure of dissolved carbon dioxide in equilibrium with dissolved species in surface sea water. The calculation of equilibrium partial pressure is described below. This simulation is not intended for the study of carbon transfer through the atmosphere between warm and cold surface reservoirs, and it does not represent this process well.

Dissolved carbon is added to the warm surface water reservoir by rivers. Carbon is removed from the ocean by incorporation into shelf sediments as organic carbon at a rate that just balances the rate of kerogen oxidation. A larger sink for dissolved carbon is the precipitation of shelf carbonate sediments at a rate proportional to the concentration of dissolved carbonate ions in warm surface water. The largest sink for oceanic carbon is the accumulation of pelagic carbonate sediments. In the long-term steady state, the rock cycle fixes the partial pressure of carbon dioxide in the atmosphere at a level that ensures that silicate weathering reactions can consume carbon dioxide as fast as it is added to the atmosphere by volcanic and metamorphic processes (Holland, 1978; Walker et al., 1981; Berner et al., 1983). On shorter time scales, however, atmospheric carbon dioxide is affected by redistribution of carbon species between atmosphere, ocean, and terrestrial biomass.

The evolution of biomass is described by a single differential equation: Rate of change of biomass equals source minus sink. The source is initially assumed to be constant at $4 \times 10^{15} \mathrm{~m} / \mathrm{y}$ (Woodwell et al., 1983; Esser, 1987; Keeling et al., 1989a). The sink is first order in biomass with a time constant of $50 \mathrm{yr}$.

The precipitation of carbonate minerals on the continental shelves and the preservation of carbonate sediments in the deep ocean depend on the partitioning of total dissolved carbon amongst the various carbon species: dissolved $\mathrm{CO}_{2}$, carbonate ions, and bicarbonate ions. This partitioning depends on the concentration of total dis- 
solved carbon and the net charge concentration of all of the dissolved species other than carbon, which we shall call alkalinity. In calculating carbonate equilibria we use effective equilibrium constants that are linear functions of temperature, $T_{\mathrm{s}}$, in degrees $\mathrm{K}$

$K_{\text {carb }}=5.75 \times 10^{-4}+6 \times 10^{-6}\left(T_{\mathrm{s}}-278\right)$

$K_{\mathrm{CO}_{2}}=0.035+0.0019\left(T_{\mathrm{s}}-278\right) \mathrm{PAL} \mathrm{m}^{3} \mathrm{~mole}^{-1}$

where $K_{\text {carb }}=K_{2} / K_{1}$ and $K_{\mathrm{CO}_{2}}=K_{2} /\left(\alpha K_{1} \times\right.$ $\left.280 \times 10^{-6} \mathrm{~atm}\right)$ from Broecker and Peng (1982, p. 151) and PAL represents the preindustrial atmospheric level of $\mathrm{CO}_{2}\left(=280 \times 10^{-6} \mathrm{~atm}\right)$. The expressions for dissolved carbon species as functions of total dissolved carbon and alkalinity are

$$
\begin{aligned}
& {\left[\mathrm{HCO}_{3}^{-}\right]=\frac{\Sigma-\sqrt{\Sigma^{2}-A(2 \Sigma-A)\left(1-4 K_{\mathrm{carb}}\right)}}{1-4 K_{\mathrm{carb}}}} \\
& {\left[\mathrm{CO}_{3}^{2-}\right]=\frac{A-\left[\mathrm{HCO}_{3}^{-}\right]}{2}}
\end{aligned}
$$$$
\left(p \mathrm{CO}_{2}\right)_{\mathrm{s}}=\frac{K_{\mathrm{CO}_{2}}\left[\mathrm{HCO}_{3}^{-}\right]^{2}}{\left[\mathrm{CO}_{3}^{2-}\right]}
$$

where $\Sigma$ is total dissolved inorganic carbon and $\mathrm{A}$ is alkalinity. $\left(p \mathrm{CO}_{2}\right)_{\mathrm{s}}$ is expressed in PAL; concentrations of dissolved species are in moles $/ \mathrm{m}^{3}$. These expressions were derived by writing $\Sigma$ equals the sum of carbonate ions, bicarbonate ions, and dissolved $\mathrm{CO}_{2}$, while $\mathrm{A}$ equals bicarbonate ions plus twice carbonate ions. One then expresses carbonate ion and dissolved $\mathrm{CO}_{2}$ in terms of $\mathrm{A}$ and bicarbonate ion and solves the resulting quadratic equation for the bicarbonate concentration. In order to keep the solution general, we have not here assumed that the concentration of dissolved carbon dioxide is negligibly small.

Total dissolved carbon, $\Sigma$, is transported between oceanic reservoirs by the thermohaline circulation and the mixing processes that exchange water between reservoirs. In addition, total dissolved carbon is carried out of the warm surface water reservoir into the underlying thermocline and deep ocean reservoirs in the form of biogenic particles of both organic carbon and calcium car- bonate minerals. This transport is taken to be proportional to organic productivity, discussed above in connection with the phosphorus budget. The ratio of organic carbon to phosphorus in the biogenic particulate rain, $R_{\mathrm{CP}}$, is assigned a value of 120 . The ratio of particulate carbonate minerals to particulate organic carbon, $R_{\mathrm{CO}}$, is set equal to 0.09 . This ratio, which refers just to calcite, controls the lysocline depth and the rate of accumulation of pelagic carbonate sediments. We could have used a larger value if we had included a flux of aragonite, which dissolves completely in the deep sea. The organic carbon is converted back into total dissolved carbon by respiration and decay processes partly in the thermocline and partly in the deep ocean reservoirs. The partitioning of organic carbon between these reservoirs is the same as the partitioning of phosphorus. A fraction $f_{\mathrm{PT}}=0.925$ is restored in the thermocline; the remainder is partitioned between deep ocean reservoirs in proportion to their areas. Both $R_{\mathrm{CO}}$ and $f_{\mathrm{PT}}$ are determined by tuning the model to reproduce observed distributions of dissolved inorganic carbon. The value of $f_{\mathrm{PT}}$ is a tuning parameter that determines the vertical gradient of $\delta^{13} \mathrm{C}$.

Sea water at shallow depths is supersaturated with respect to carbonate minerals while deep water is undersaturated, partly because of the temperature dependence of the carbonate solubility but largely because of the pressure dependence. Carbonate particles therefore do not dissolve in the thermocline reservoir but continue on into the deep ocean reservoirs. The fraction of the particulate carbonate flux into the deep ocean reservoirs that dissolves depends on the carbonate saturation state of these reservoirs. We characterize this saturation state in terms of the depth of the lysocline, taken in this simulation to be a depth below which dissolution of carbonate particles is complete and above which no dissolution occurs. The carbonate saturation state of a deep ocean reservoir depends on the concentration of carbonate ions in that reservoir. The concentration of calcium ions varies negligibly between ocean reservoirs on the time scales of this study. Calcium ion concentrations are therefore assumed to be constant. The depth of the lysocline, 
$z_{\mathrm{ly}}$, is taken to be a linear,function of the carbonate ion concentration (in moles $/ \mathrm{m}^{3}$ )

$z_{\mathrm{ly}}=z_{1}+z_{2}\left(\left[\mathrm{CO}_{3}^{2-}\right]-0.1\right)$

The coefficient $z_{1}=5.8 \mathrm{~km}$ determines the overall depth of the lysoclines in the three deep ocean reservoirs and therefore the overall rate of accumulation of pelagic carbonates. It is adjusted in procedures described below. The parameter $z_{2}$ describes how rapidly lysocline depth changes with changing carbonate ion concentration. Its value of $50 \mathrm{~km} /\left(\mathrm{mole} / \mathrm{m}^{3}\right)$ was deduced from results presented by Broecker and Peng (1982, p. 283). The lysocline depth for each ocean basin is then combined with average total ocean hypsometry presented by Menard and Smith (1966) to calculate the fraction of the area of each basin that lies below the lysocline. This is the fractional area of each ocean bottom exposed to undersaturated water. We assume that productivity and the rain of carbonate particles is spatially homogeneous, so the proportion of this rain that dissolves in each deep ocean reservoir is proportional to the area of the basin below the lysocline. The remaining flux of carbonate particles settles to the bottom in water supersaturated with respect to calcium carbonate and accumulates as pelagic carbonate sediments. This carbon is removed at least temporarily from the ocean-atmosphere system. The carbonate particles that dissolve in the deep ocean reservoirs add total dissolved carbon and alkalinity to these reservoirs. The rate of precipitation of shelf carbonate sediments, which is small in this simulation, is taken to be proportional to the concentration of carbonate ions in warm surface water. The expression we use for this rate is presented in Section 5.1 .

\subsubsection{Temperature}

A single differential equation describes the evolution of global average surface temperature, $\mathrm{T}_{s}$ (degrees $\mathrm{K}$ )

$\frac{\mathrm{d} T_{\mathrm{s}}}{\mathrm{d} t}=\frac{Q-F_{\mathrm{IR}}\left(T_{\mathrm{s}}\right)}{C_{\mathrm{suri}}}$

The source term in this equation is global average insolation

$Q=\frac{1.365}{4}(1-\alpha) W^{-2}$ where the albedo, $\alpha$, equals 0.3 (Ramanathan et al., 1989). The sink term is the outgoing flux of long-wave infrared radiation, a linear function of global average surface temperature

$F_{\mathrm{IR}}\left(T_{\mathrm{s}}\right)=A_{\mathrm{IR}}+B_{\mathrm{IR}} T_{\mathrm{s}} \mathrm{Wm}^{-2}$

(Marshall et al., 1988). The coefficients in this expression depends on the partial pressure of carbon dioxide as follows

$A_{\mathrm{IR}}=-352.08+9.56 \ln \left(p \mathrm{CO}_{2}\right)$

$B_{\mathrm{IR}}=2.053-0.0514 \ln \left(p \mathrm{CO}_{2}\right)$

with $p \mathrm{CO}_{2}$ expressed in PAL. The effective heat capacity, $C_{\text {surf }}$, used in the calculation of surface temperature evolution is 50 joule $\mathrm{s} / \mathrm{m}^{2} / \mathrm{deg} / \mathrm{yr}$. The time units $(\mathrm{s} / \mathrm{yr})$ enter in because time in this calculation is measured in years while the energy fluxes are in $\mathrm{W} / \mathrm{m}^{2}$. This heat capacity is equivalent to a column of water $377 \mathrm{~m}$ thick, a thickness appropriate to global warming on a time scale of decades.

The temperature of cold surface water and the temperature of the deep ocean reservoirs are fixed at $2^{\circ} \mathrm{C}$. The temperature of the warm surface water reservoir is calculated from global average surface temperature and the fraction of the globe covered by cold surface water at a temperature of $2^{\circ} \mathrm{C}$. This fraction is taken to be 0.0025 . In this calculation the temperature plays a role only in determining the values of carbonate equilibrium coefficients. These equilibrium coefficients are different for warm surface water and for the cold ocean reservoirs. The difference in the equilibrium constants and thus in the carbon speciation between warm and cold surface water depends on atmospheric carbon dioxide partial pressure through the greenhouse effect.

In a future study we might calculate also the temperature of the various water masses, providing thermal constraints on the assumed circulation and permitting possible explanation of the effects on climate and carbon dioxide of assumed changes in circulation.

\subsubsection{Alkalinity}

Alkalinity is defined in this simulation as the sum of the biocarbonate ion concentration and twice the carbonate ion concentration. It is the 
net concentration of charge on the dissolved carbon species. Its importance is that the requirement of overall charge neutrality implies that alkalinity must be equal to the net positive charge on all dissolved species other than the carbon species. Alkalinity therefore depends on the concentration of other dissolved charged species, and it controls the speciation of total dissolved carbon.

Alkalinity is provided to the warm surface water reservoir by rivers, being supplied by dissolution of terrestrial carbonate rocks and silicate rocks. It is removed from the ocean by the precipitation of carbonate sediments on the shelves and on the deep sea floor. The way in which pelagic carbonate accumulation rate depends on the rain of carbonate particles of biological origin and on the saturation state of the deep ocean reservoirs has been described above in the sub-section on carbon.

Alkalinity is transported between ocean reservoirs by fluxes of water associated with the thermohaline circulation and mixing processes. It is extracted from the warm surface water reservoir by the formation of calcium carbonate particles at a rate proportional to productivity, and it is restored to deep ocean reservoirs by the dissolution of these calcium carbonate particles at a rate proportional to the area of the deep sea floor overlain by undersaturated water. In addition, there is a small transport of alkalinity associated with the formation of organic nitrogen from dissolved nitrate in the warm surface water reservoir and the restoration of nitrate in the thermocline and deep sea reservoirs. This nitrogen transport is directly proportional to the transport of organic carbon. Because of the negative charge on dissolved nitrate the transport of alkalinity by descending particles of organic matter is upward. The ratio of alkalinity transport to organic carbon transport is 0.15 (Broecker and Peng, 1982).

\subsubsection{Carbon isotopes}

The conservation equations for carbon isotopes are, of course, directly related to the conservation equations for carbon. There is isotopic fractionation when carbon dioxide dissolves in sea water with a value that depends on temperature according to

$\Delta C_{S}^{13}(\% 0)=9.5-\left(T_{s}-298\right) / 10$

where $T_{\mathrm{s}}$ is expressed in degrees $\mathrm{K}$ (Mook et al., 1974; Broecker and Peng, p. 310). There is a different isotopic fractionation for carbon dioxide coming out of the solution. Its value is $\Delta \mathrm{C}_{\mathrm{A}}^{13}=$ 16\% (Siegenthaler and Munnich, 1981). These fractionation coefficients refer to ${ }^{13} \mathrm{C}$ relative to ${ }^{12} \mathrm{C}$. In all cases, the fractionation coefficients for ${ }^{14} \mathrm{C}$ are twice as large. Terrestrial photosynthesis produces isotopically light organic carbon, with a fractionation relative to atmospheric carbon dioxide of $20 \%$ for ${ }^{13} \mathrm{C}$ and $40 \%$ for ${ }^{14} \mathrm{C}$. Photosynthesis in the warm surface water reservoir also fractionates, by $25 \%$ for ${ }^{13} \mathrm{C}$ and by twice as much for ${ }^{14} \mathrm{C}$ (Anderson and Arthur, 1983). This fractionation is with respect to the carbon isotopic composition of warm surface water. Carbonate minerals are assumed to be slightly fractionated with respect to dissolved carbon, by $1.7 \%$ for ${ }^{13} \mathrm{C}$ and by twice as much for ${ }^{14} \mathrm{C}$ (Anderson and Arthur, 1983). The overall level of the ${ }^{13} \mathrm{C}$ ratio in the ocean is determined by the rock cycle and the rates of carbonate dissolution, kerogen oxidation, volcanic release of carbon dioxide, and accumulation of organic carbon in shelf sediments.

In addition to the fractionation between reservoirs already described, radiocarbon is affected by radioactive decay with a decay time equal to 8267 yr (Broecker and Peng, 1982). In the steady state, this decay is balanced by an atmospheric source provided by the interaction of cosmic rays with atmospheric nitrogen. This is the only source for radiocarbon, but radioactive decay occurs in all of the carbon reservoirs, atmosphere, terrestrial biomass, and ocean.

\section{Tuning the model}

The coefficients that control the rates of exchange of carbon between reservoirs are adjusted to yield reasonable agreement between the simulation and observations. The process is known as tuning. We shall approach the tuning process in a systematic manner, seeking values for the various 
coefficients that can be left unchanged for the rest of the calculations described in this paper. We seek to arrive at a single simulation that can describe the response of the biogeochemical cycles of carbon on a variety of time scales, yielding reasonable agreement with such observations as are available.

We begin with observations of radiocarbon produced by atmospheric testing of nuclear weapons during the middle decades of the $20^{\text {th }}$ century. These observations constrain the rates of exchange of carbon between the atmosphere, biomass, and surface ocean reservoirs. We consider next the long-term steady state distribution of carbon and its isotopes in atmosphere and oceanic reservoirs as well as the distribution of dissolved phosphorus in the ocean and the saturation state of the deep ocean. These observations constrain the biogeochemical circulation of the ocean. With the ocean simulation calibrated in this manner we shall in the next section test the simulation by applying it to the historical record of change brought about by the industrial revolution.

\subsection{Bomb radiocarbon}

Important information about the exchange of carbon between the atmosphere and adjacent reservoirs on a time scale of years is provided by the response of atmospheric radiocarbon to the very large source resulting from atmospheric testing of nuclear weapons in the 50's and 60's (Broecker and Peng, 1982). The markers in Fig. 5 show the observed history of radiocarbon in the atmosphere and in warm surface water, and the solid lines show the simulated response of these reservoirs and the cold surface water reservoir during the period 1950 to 1976 . The data are from Broecker and Peng (1982, p. 389). In calculating this history we assumed for the rate of production of radiocarbon in the atmosphere the values shown in Fig. 6. The history of this source is based on observations of the rate of fall-out of tritium and radioactive strontium (Broecker and Peng, 1982, pp. 386-387). We assumed that the radiocarbon source was proportional to the fallout rate. The amplitude of the source, with a

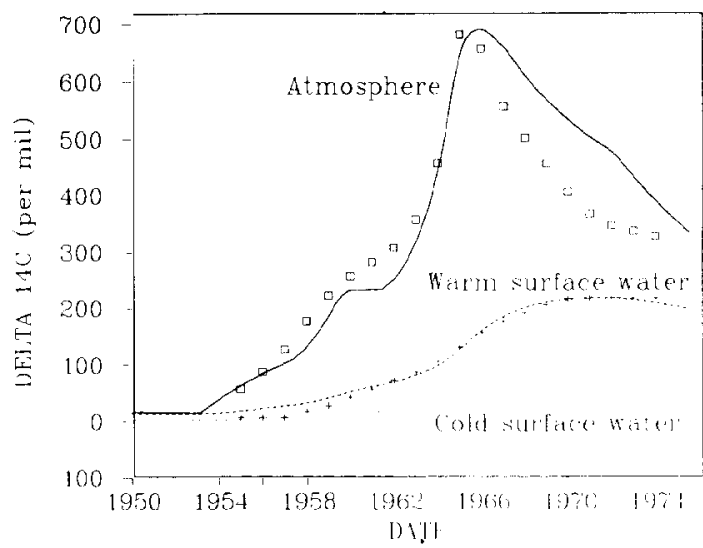

Fig. 5. Calculated response of the atmosphere and surface ocean reservoirs to the input of bomb radiocarbon. Observations of radiocarbon response are indicated by the markers.

peak value approaching $45,000 \mathrm{~m} / \mathrm{y}$, was adjusted to yield the correspondence between theory and observation shown in Fig. 5.

Because of the short time involved in the response to bomb radiocarbon, the computed results are sensitive mainly to the rate of exchange of carbon between atmosphere and biomass and between atmosphere and surface water reservoirs. The rate of mixing of the surface water reservoirs with the thermocline also has an effect, but the response of the system on this time scale is not sensitive to the thermohaline circulation. The evolution of the biomass reservoir will be

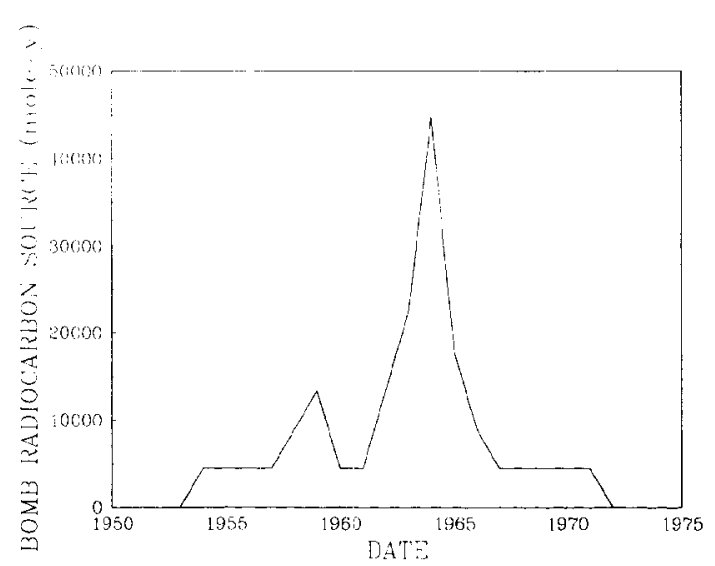

Fig. 6. The history of the bomb radiocarbon source. The source is assumed proportional to the concentration of strontium in fallout. The proportionality constant is adjusted to achieve the agreement between theory and observation illustrated in Fig. 5. 
discussed in more detail below. As already noted it had an initial mass of $2 \times 10^{17}$ moles of carbon. By 1950 , in this simulation, this mass had hardly changed. Exchange of carbon between atmosphere and biomass was assumed to depend on atmospheric carbon dioxide partial pressure and to be first order in biomass, with a residence time of carbon in the biomass reservoir equal to $50 \mathrm{yr}$. These parameters were not adjusted to reproduce the radiocarbon response shown in Fig. 5, but were adjusted to reproduce the 100 -yr history of carbon isotopes and atmospheric carbon dioxide in a tuning process discussed below.

The parameters that were adjusted to reproduce the radiocarbon response are the rate of exchange of carbon between atmosphere and surface water and the rate of exchange between the warm surface water reservoir and the thermocline. The carbon flux between atmosphere and surface water is proportional to the difference between atmospheric partial pressure and the partial pressure in equilibrium with the concentrations of dissolved carbon species in the surface water. The expression for the carbon flux is

$F_{\mathrm{OA}}=\frac{\left[\left(p \mathrm{CO}_{2}\right)_{\mathrm{s}}-p \mathrm{CO}_{2}\right] A_{\mathrm{s}} M_{\mathrm{atm}}}{\tau_{\mathrm{OA}}}$

where $\left(p \mathrm{CO}_{2}\right)_{\mathrm{s}}$ is the equilibrium partial pressure and $p \mathrm{CO}_{2}$ the atmospheric value, both in PAL. $M_{\text {atm }}$ is the amount of carbon dioxide in the preindustrial atmosphere, $4.95 \times 10^{15}$ moles. The total exchange between the atmosphere and each of the surface water reservoirs is proportional to the fractional area, $A_{\mathrm{s}}$, of that reservoir. A value for the proportionality constant of $\tau_{\mathrm{OA}}=$ 10 years was deduced from the comparison between calculation and observation shown in Fig. 5 and was used in all of the calculations presented in this paper. The tuned value of this parameter depends on the volumes and carbon contents of the surface ocean reservoirs.

As pointed out by Broecker and Peng, the bomb radiocarbon data provide an additional constraint on the system, related to how quickly the added radiocarbon is mixed down into the thermocline. This constraint takes the form of the total amount of bomb radiocarbon in the ocean in 1973. The measured value, reported by Broecker and Peng (1982, p. 548), was $3.14 \times 10^{28}$ atoms. The calculated value in this simulation was $3.09 \times 10^{28}$ atoms. This calculated value depends on the rate of mixing between the warm surface water reservoir and the thermocline. This rate was adjusted to yield the agreement just reported. The deduced value of the mixing parameter was a vertical mixing velocity of 10.5 $\mathrm{m} / \mathrm{y}$. Thus the total amount of water per year exchanged between the warm surface water reservoir and the thermocline is the area of the reservoir times $10.5 \mathrm{~m}$. Alternatively, the residence time of warm surface water before it is mixed into the thermocline is a thickness of $75 \mathrm{~m}$ divided by the vertical mixing velocity of 10.5 $\mathrm{m} / \mathrm{y}$, approximately $7 \mathrm{yr}$.

In adjusting the simulation to reproduce the observations shown in Fig. 5, then, we determine the values of the three parameters: amplitude of the bomb radiocarbon source, exchange coefficient between atmosphere and surface water, and mixing coefficient between warm surface water and thermocline. The three observations that constrain the values of these parameters were: the history of radiocarbon in the atmosphere, the history of radiocarbon in warm surface water, and the total amount of radiocarbon in the ocean in 1973. The mixing and exchange parameters just specified were not changed for any of the remaining calculations presented in this paper. The model used for the calculations shown in Fig. 5 was the fully developed and tuned model that we are in the course of describing. Because we make no further use of bomb radiocarbon results, for the rest of this paper the bomb radiocarbon source will be set to zero.

\subsection{Pre-industrial steady state}

In this section we tune the oceanic component of the model by adjusting exchange fluxes between oceanic reservoirs to reproduce with reasonable fidelity the distribution of tracers in the sea. This process involves a fair amount of iteration, but in order to keep the development clear we shall describe the tuning strategy in a way that associates observable parameters of the model 
TABLE 2

Preindustrial steady state concentrations

\begin{tabular}{lllllll}
\hline Reservoir & Phosphate & $\mathrm{\Sigma}$ & $\mathrm{A}$ & $\mathrm{HCO}_{3}^{-}$ & $\mathrm{CO}_{3}^{2-}$ & $\left(p \mathrm{CO}_{2}\right)_{\mathrm{eq}} * *$ \\
\hline Warm surface & 0.10 & 1.96 & 2.12 & 1.78 & 0.171 & 0.996 \\
Cold surface & 0.96 & 2.07 & 2.12 & 1.96 & 0.078 & 1.45 \\
Deep Atlantic & 1.22 & 2.12 & 2.15 & 2.02 & 0.067 & 1.79 \\
Deep Indian & 1.51 & 2.18 & 2.20 & 2.08 & 0.059 & 2.16 \\
Deep Pacific & 2.50 & 2.40 & 2.38 & 2.29 & 0.046 & 3.34 \\
Thermocline & 1.25 & 2.11 & 2.12 & 2.01 & 0.053 & 2.26
\end{tabular}

* Phosphate concentrations in millimoles $\mathrm{m}^{-3} ; * * \mathrm{CO}_{2}$ in PAL $\left(1 \mathrm{PAL}=280 \times 10^{-6} \mathrm{~atm}\right)$; all other concentrations in moles $\mathrm{m}^{-3}$.

with the adjustable parameters that influence them most strongly. The targets of this tuning process are the distribution of total dissolved carbon and dissolved phosphate in the various oceanic reservoirs, shown in Fig. 7 and the distribution of ${ }^{13} \mathrm{C}$ and ${ }^{14} \mathrm{C}$ in the oceanic reservoirs and in the atmosphere, shown in Fig. 8. Numerical values of dissolved carbon and phosphate and other carbonate species are listed in Table 2.

In this section we tune the oceanic component of the model by adjusting exchanges fluxes between oceanic reservoirs to reproduce with reasonable fidelity the distribution of tracers in the sea. This process involves a fair amount of iteration, but in order to keep the development clear we shall describe the tuning strategy in a way that associates observable parameters of the model with the adjustable parameters that influence them most strongly. The targets of this tuning

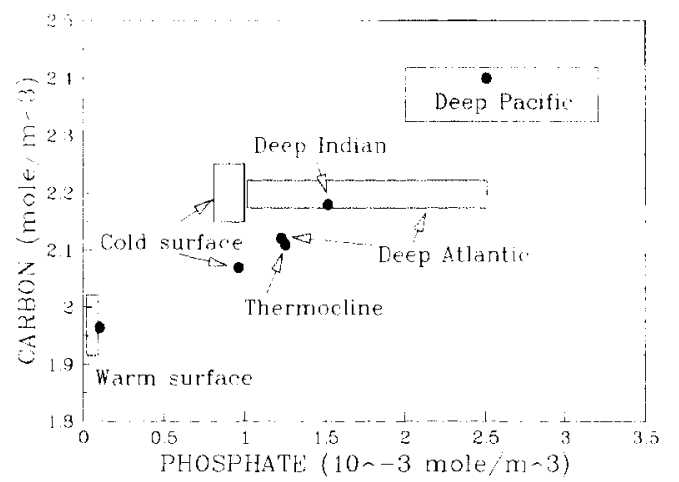

Fig. 7. The steady state distribution of dissolved phosphate and total dissolved carbon in the ocean. The points are calculated values, while observations are indicated by rectangles (Broecker and Peng, 1982, p. 70). process are the distribution of total dissolved carbon and dissolved phosphate in the various oceanic reservoirs, shown in Fig. 7 and the distribution of ${ }^{13} \mathrm{C}$ and ${ }^{14} \mathrm{C}$ in the oceanic reservoirs and in the atmosphere, shown in Fig. 8. Numerical values of dissolved carbon and phosphate and other carbonate species are listed in Table 2.

The spread in radiocarbon ratios between cold surface water and the deep Pacific water depends mainly on how long it takes water to travel in the thermohaline circulation from the cold surface reservoir through the deep Atlantic and deep Indian reservoirs to the deep Pacific reservoir. This deep sea ventilation time is controlled by the vertical upwelling velocity that carries water from the deep ocean reservoirs into the thermocline at fluxes proportional to the areas of the deep sea reservoirs. This upwelling velocity is adjusted to reproduce as closely as possible the observed

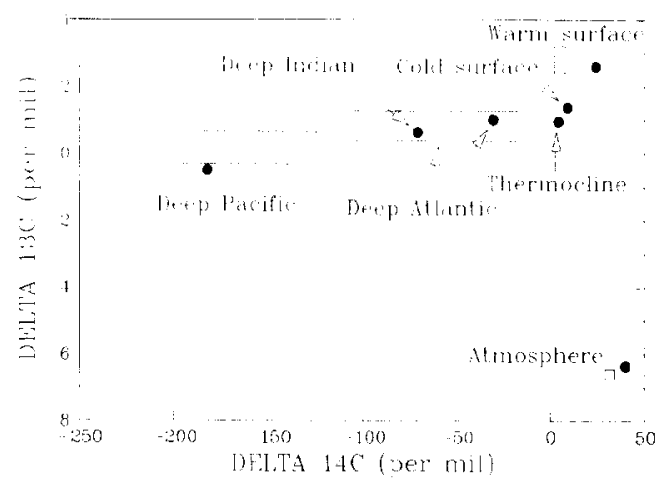

Fig. 8. The steady state distribution of carbon isotopes in ocean and atmosphere. The calculated values are indicated by points while observations are represented by rectangles (Broecker and Peng, 1982, pp. 249-252, 309). 
radiocarbon age of deep Pacific water. The adjusted value is $1.15 \mathrm{~m} / \mathrm{y}$. The absolute values of radiocarbon depend on the magnitude of the atmospheric source of radiocarbon and also on the total dissolved carbon content of ocean and atmosphere. The deduced value of the radiocarbon source is $506.22 \mathrm{~m} / \mathrm{y}$, within the range of values reported by O'Brien (1979) and Stuiver and Quay (1980). The difference in radiocarbon ratios between atmosphere and surface water is controlled by the exchange parameters already determined in the tuning to bomb radiocarbon observations.

The next tuning target is the distribution of phosphate in the deep ocean reservoirs. In this simulation the phosphate content of warm surface water is determined by the rock cycle, because the marine sink of dissolved phosphate is proportional to the phosphate concentration in warm surface water and the river source of phosphate is fixed. Because we have assumed that the phosphate concentration of warm surface water is a fixed fraction, $f_{\mathrm{PD}}=0.04$, of the phosphate concentration in deep Pacific Water, the concentration in deep Pacific water is also fixed. The parameters are such that the concentration in warm surface water is $0.1 \times 10^{-3}$ moles $/ \mathrm{m}^{3}$ and the concentration in deep Pacific water is $2.5 \times$ $10^{-3}$ moles $/ \mathrm{m}^{3}$. The goal of the tuning exercise is to yield a spread between these limiting values of concentrations in the deep Atlantic and deep Indian ocean reservoirs that is reasonably close to observations. With the ocean simulation as structured here, the tuning parameter is the fraction of particulate phosphate that dissolves in the thermocline as opposed to the fraction that dissolves in the deep ocean reservoirs. In this simulation the thermocline reservoir is uniform across all ocean basins and so does not contribute to the difference between Atlantic and Pacific Oceans. If little phosphorus survives dissolution in the thermocline reservoir to settle into the deep ocean there will be little difference between the phosphate concentrations in the different deep sea reservoirs. Therefore an increase in the fraction of phosphorus dissolving in the thermocline results in an increase in the phosphate concentration in the deep Atlantic reservoir. For the re- sults shown in Fig. 7, it was assumed that a fraction $f_{\mathrm{PT}}=0.925$ of particulate phosphate dissolves in the thermocline reservoir.

The tuning exercises already carried out have fixed the phosphate concentration in the various oceanic reservoirs as well as the fluxes of water between these reservoirs. These quantities in turn determine the biological productivity of the warm surface water reservoir, which depends on the flux into the reservoir of dissolved phosphate. The difference in the ${ }^{13} \mathrm{C}$ ratios in the surface water reservoir and the deep ocean reservoirs then depends on the carbon to phosphorus ratio in the descending particles of organic matter. This same ratio controls also the gradient in carbon isotope ratio between the deep Atlantic reservoir, which accumulates relatively little organic debris, and the deep Pacific reservoir, which accumulates a lot. An increase in the carbon to phosphorus ratio in biogenic particles reduces the value of the ${ }^{13} \mathrm{C}$ ratio in the deep Pacific reservoir. The results in Fig. 8 correspond to a carbon to phosphorus ratio $R_{\mathrm{CP}}=120$ atoms of carbon per atom of phosphorus. This value is close to the Redfield ratio, with some allowance for preferential dissolution of phosphorus. The difference between carbon isotopes in the atmosphere and in surface water is not subject to adjustment, but depends on the equilibrium isotope fractionation factor. The absolute values of the isotope ratios in the ocean-atmosphere system are controlled by the rock cycle. The most important controlling factors are the isotope ratio in the carbon supplied by carbonate dissolution, for which we use a value of $+1.32 \%$, the isotope ratio in volcanic and metamorphic carbon dioxide, for which we use a value of $-0.7 \%$, and the fractionation involved in the precipitation of carbonate minerals, for which we use a value of $-1.7 \%$ relative to warm surface sea water. These values result in a steady state isotopic composition for the pre-industrial atmosphere of $-6.35 \%$, close to that derived from measurements on bubbles in polar ice (Friedli et al., 1986) or from the changes deduced from studies of tree rings (Freyer, 1986). The difference in lysocline depths between Atlantic, Indian, and Pacific Oceans depends on the carbonate ion concentrations in these reservoirs 
and therefore on the relative additions of biogenic carbon and calcium carbonate. An increase in the ratio of calcium carbonate to organic carbon in the biogenic particles causes an increase in the Pacific lysocline depth relative to the Atlantic lysocline depth. We use a value of $R_{\text {CO }}=0.09$ for this ratio, which results in lysocline depths of $4.15,3.74$, and $3.10 \mathrm{~km}$ in the Atlantic, Indian, and Pacific Oceans. The corresponding fractional areas of these ocean basins bathed in supersaturated water are $0.50,0.41$, and 0.29 .

The overall level of total dissolved carbon and alkalinity in the ocean is constrained by the requirement that carbonates be deposited as rapidly as they are being added to the ocean by carbonate dissolution, weathering, and volcanism. In the steady state, the atmospheric pressure of carbon dioxide is fixed by the rock cycle, as already noted, so only one parameter is subject to further adjustment. This parameter is the constant $z_{1}$ in the expression for lysocline depth as a function of carbonate ion concentration. We use a value of $5.8 \mathrm{~km}$ for this constant to derive the steady state values of total dissolved carbon shown in Fig. 7. This value is not strictly in accord with the solubility constant for calcite. Our simulation does not deal with additional factors affecting lysocline depth such as the oxidation of organic carbon within the bioturbation zone and the variation with depth of carbonate ion concentration in the deep sea.

The tuning process is iterative because adjustments to some of the parameters described later in this section cause changes in some of the observable quantities referred to earlier. The values quoted in this discussion and illustrated in Fig. 9 are the final results of this iterative tuning process. Some of the parameters of the simulation have little effect on the results and so have values that can not be determined in the tuning process. These include the mixing processes that exchange water between the surface water reservoirs and between the thermocline and the cold surface water reservoir. These mixing fluxes are given by the volume of the warm surface water reservoir divided by a mixing time of $50 \mathrm{yr}$ for exchange between the surface water reservoirs and by the volume of the thermocline divided by a mixing

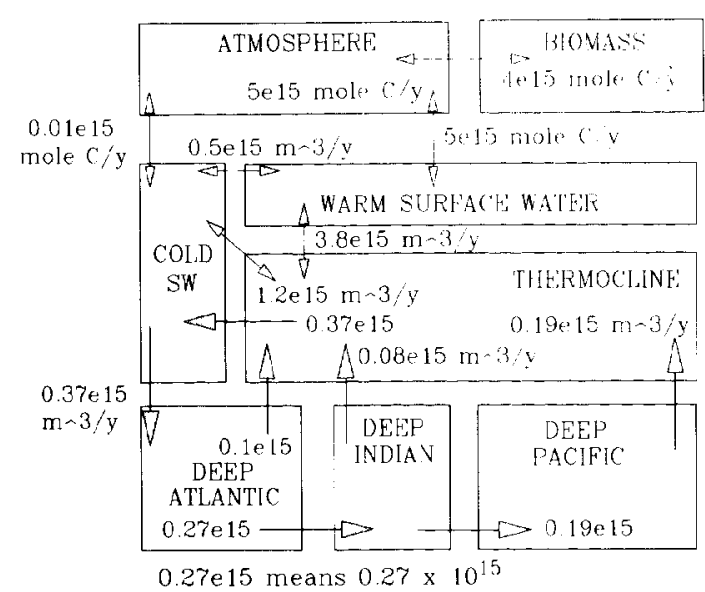

Fig. 9. Exchange fluxes in the simulation tuned to yield the steady state values of Figs. 7 and 8 , and the bomb radiocarbon history of Fig. 5. Oceanic fluxes are stated in terms of volumes of water exchanged per year. The fluxes connecting to the atmosphere are quoted in terms of moles carbon per year.

time of $250 \mathrm{yr}$ for exchange between the thermocline and the cold surface water reservoir.

\section{Industrial revolution}

The computer simulation has been described in previous sections. We have shown how the parameters of the simulation can be adjusted, in a process known as tuning, to reproduce observations. The particular observations we have used to tune this simulation are the record of bomb radiocarbon in the atmosphere and ocean and the pre-industrial distribution in the ocean of carbon isotopes, phosphorus, and total dissolved carbon. In this section we apply the simulation to the observed record of atmospheric carbon dioxide and carbon isotopes during the industrial revolution. This comparison of theory and observation will reveal some inadequacies in the simulation. We will introduce additional features into the simulation that improve the agreement of the theory with observations.

\subsection{Fossil fuel}

For the first numerical simulation of the industrial revolution we add a source of atmospheric carbon dioxide corresponding to the burning of fossil fuel. All other parameters of the simulation 


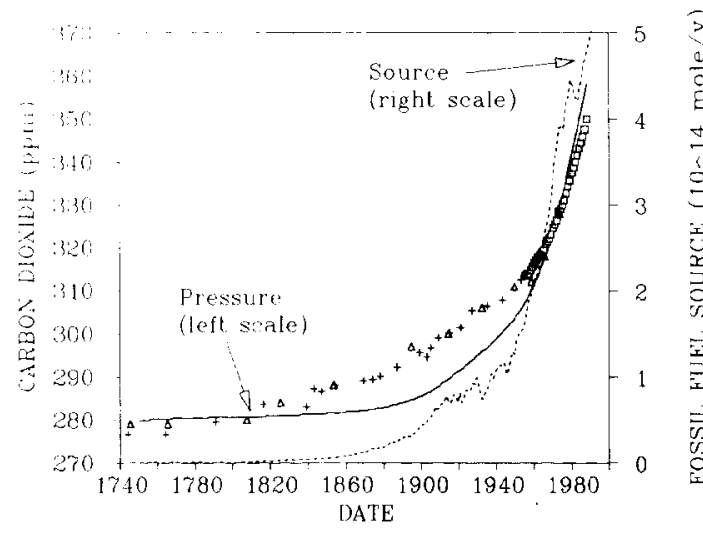

Fig. 10. History of carbon dioxide during the last few centuries. Observations are indicated by markers. The calculated values are indicated by solid lines. The response of the system is driven by fossil fuel combustion only, with the fossil fuel source as shown by the dashed line.

are left unchanged. Figure 10 shows the fossil fuel source, the observed atmospheric partial pressure of carbon dioxide, and the calculated partial pressure. The fossil fuel source is based on a tabulation by Keeling et al. (1989a). The observations of atmospheric carbon dioxide partial pressure are from Keeling et al. (1989a) since 1958 and from Neftel et al. (1985) and Friedli et al. (1986) for the older record. The pre-1958 data are derived from air bubbles in polar ice.

Both calculated and observed carbon dioxide mixing ratios equal about 280 parts per million prior to 1800 . Indeed, the simulation was tuned in the previous section to reproduce this pressure. The observed carbon dioxide values show a steady increase during the $19^{\text {th }}$ century and the first half of the $20^{\text {th }}$ century and a more rapid increase in the second half of the $20^{\text {th }}$ century. This failure is a direct consequence of the very small values of fossil fuel release rate during most of the $19^{\text {th }}$ century. In this simulation the only perturbation is carbon dioxide from fossil fuel burning. The rate of this process was negligibly small before about 1850 . Therefore the simulation shows no response before about 1850 . The observed increase in carbon dioxide during the $19^{\text {th }}$ century is not due principally to fossil fuel burning but almost certainly due to forest clearance in the so called pioneer effect (Woodwell et al., 1983; Hobbie et al., 1984). We will take up the pioneer effect in the next section, but first let us examine the isotope results.

Figure 11 compares the calculated radiocarbon ratio in the atmosphere with observations based on measurements of carbon preserved in tree rings. The observations are from Stuiver (1982, 1986). Also shown in the figure are calculated values of the radiocarbon ratio in the surface ocean. The fluctuations in measured radiocarbon values in the earlier part of the record are associated with changes in solar activity and in the cosmic ray source of radiocarbon in the atmosphere (Stuiver and Quay, 1980). We have made no attempt to simulate these changes. The point of interest in this study is the rapid decrease in radiocarbon in the $20^{\text {th }}$ century caused by the release of fossil fuel carbon dioxide. Because of the great age of fossil fuels, they contain no radiocarbon.

The agreement between theory and observation for atmospheric radiocarbon is good. Since the source, fossil fuel carbon dioxide, is fairly well. determined, and the radiocarbon content of this source is well known, namely zero, this agreement relates mainly to the size of the reservoirs exchanging carbon with the atmosphere on a time scale of decades. The agreement indicates that our simulation has about the right rate of exchange of carbon between surface ocean and atmosphere and about the right rate of exchange of carbon between the biomass and the atmo-

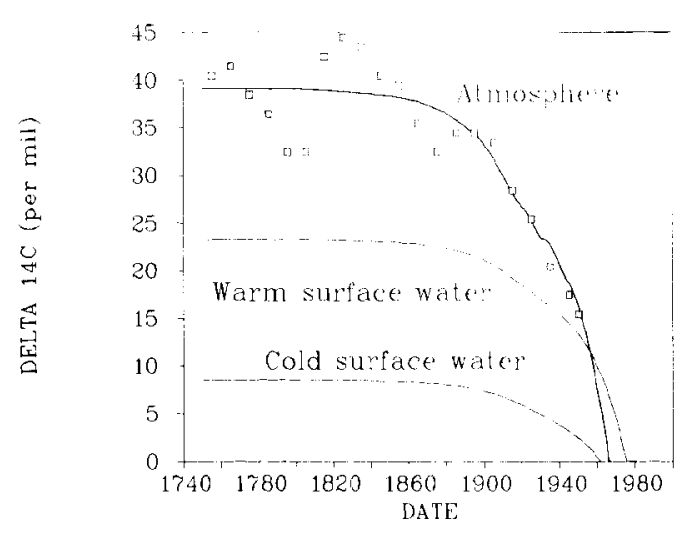

Fig. 11. Response of radiocarbon in atmosphere and surface ocean reservoirs to combustion of fossil fuel over the last few centuries. Theoretical results are plotted as solid lines. The markers are observations. 


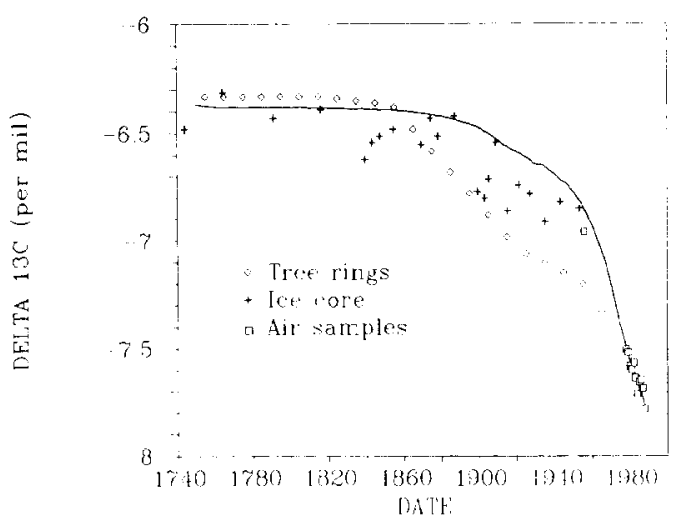

Fig. 12. Response of atmospheric ${ }^{13} \mathrm{C}$ to combustion of fossil fuel. Observations are indicated by markers, the calculations by a solid line

sphere. Since the simulation has already been tuned to reproduce the history of bomb radiocarbon in ocean and atmosphere, a history with more or less the same time scale, it is perhaps not surprising that the agreement between theory and observation for atmospheric radiocarbon is good.

Theory and observation are compared for stable carbon, ${ }^{1.3} \mathrm{C}$ in Fig. 12. The calculations use values for the isotope ratio in fossil fuel carbon as a function of time tabulated by Keeling et al. (1989a) and plotted in Fig. 13. The ratio has changed with time as a result of changing proportions of coal, oil, and natural gas consumed. The observations of atmospheric isotope ratio are based on direct mass spectrometer measurements of atmospheric carbon dioxide reported by Keeling et al. (1989a) for the period since 1958. The older data are based on tree ring measurements

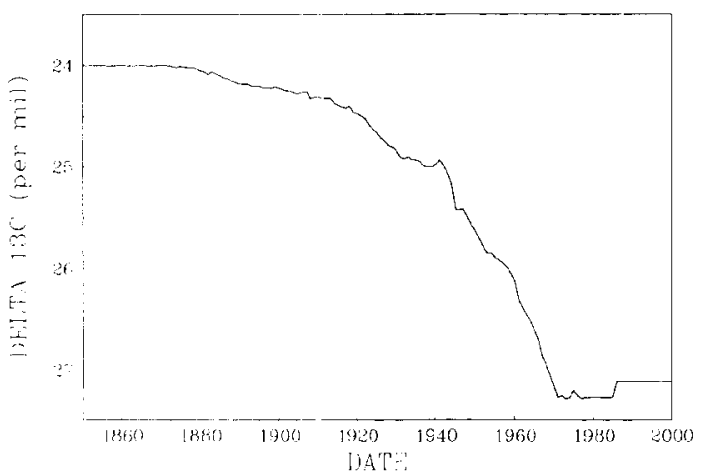

Fig. 13. The history of the average isotopic composition of fossil fuel carbon. summarized by Freyer (1986) and on ice core measurements by Friedli et al. (1986). Fossil fuel carbon is isotopically light, so the burning of fossil fuels has caused a reduction in the isotope ratio in the atmosphere. Agreement between calculation and observation is reasonably good.

\subsection{Pioneer effect}

The problems with atmospheric carbon dioxide identified here have been encountered in previous studies of the carbon cycle (e.g., Enting and Pearman, 1986; Post et al., 199()). It is clear that there has been an important contribution to the carbon cycle associated with the clearance of forests as part of the spread of population, particularly in the temperate mid-latitudes of the Northern Hemisphere in the $19^{\text {th }}$ century and in the tropics in the latter half of the $20^{\text {th }}$ century. The process is called the pioneer effect in reference to the activities of colonial pioneers.

Careful studies of land use over the globe have been carried out by Woodwell et al., (1983; Houghton et al., 1983; Houghton, 1986) to assess the history of the flux of carbon dioxide to the atmosphere caused by forest clearance. These studies assemble data on changes in the area of different kinds of agricultural and natural biomes. These estimates of areal change are combined with estimates of carbon storage per unit area (Schlesinger, 1986), assumed to be constant for a given land use class, to derive a rate of release of carbon dioxide. Integration of these rates of release over all land use classes yields a global flux of carbon dioxide to the atmosphere associated with changing land use patterns (Houghton et al., 1983; Detwiler and Hall, 1988). This history of biomass flux is plotted as points in Fig. 14. The solid line that goes through these points is the flux that actually enters into the simulation. For reasons that will be explained below, we have chosen not to use the biomass flux as a fixed and tabulated value but instead as the solution to a differential equation. Our differential equation calculates the evolution of total biomass in response to changing land use patterns and possibly other perturbations (there are related equations for the carbon isotopic composition of biomass). 


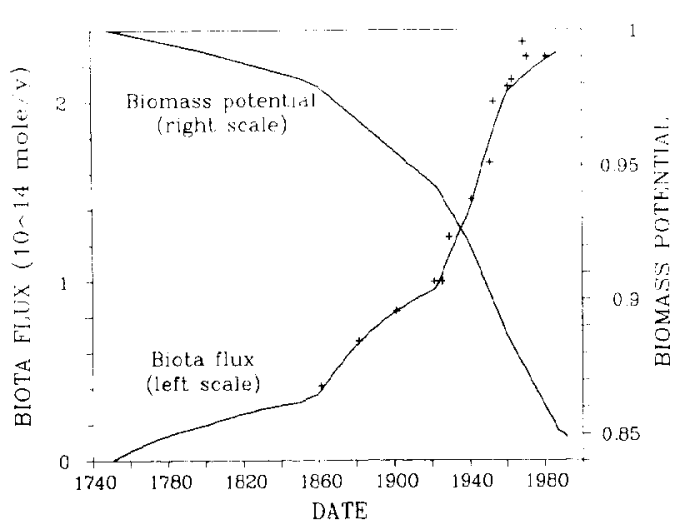

Fig. 14. The history of the flux of carbon from biota to atmosphere caused by changes in land use (forest clearance). Values deduced from land use studies appear as markers. The calculated fit to these values with the assumption of no change with time in carbon storage unit per area is plotted as a solid line. referring to the left-hand scale. The history of biomass potential has been tuned to yield the illustrated values of biota flux. The derived values of biomass potential are plotted by a solid line referring to the right-hand scale.

The differential equation is

$$
\frac{\mathrm{d} M_{\mathrm{Bi}}}{\mathrm{d} t}=\frac{F_{\mathrm{Bio}}-M_{\mathrm{Bio}}}{50}
$$

where the first term represents the growth of new biomass in units of moles per year and the second term represents the decay of old biomass, described here as a first order decay process with an effective decay time of $50 \mathrm{yr}$. The real situation is of course much more complicated. Some biomass decays rapidly. Some survives for long periods of time (Goudrian, 1989). The $50 \mathrm{yr}$ residence time represents an average that might be appropriate to the more massive components of total biomass. The initial value of $F_{\text {Bio }}$ is $2 \times 10^{17}$ moles, equal to the initial value of $M_{\mathrm{Bio}}$.

The actual record of changing land use involves a mosaic of different changes between forest and agriculture, between forest and different kinds of forest, between different agricultural uses, and between agriculture and desert. In order to greatly simplify the system without destroying its essentially dynamic features we represent the source of biomass as proportional to a quantity we call biomass potential, $B_{\mathrm{p}}$. Biomass potential is loosely defined as an integral of area weighted by carbon storage per unit area, normal- ized to 1 at the beginning of the industrial revolution. Forest clearance, then, reduces biomass potential from its initial value of 1 . In this way, we use a single number to represent a whole multiplicity of changes in land use. We then adjust the history of biomass potential in such a way as to reproduce the biomass changes that have been deduced from studies of the history of land use. The components of this calculation are shown in Fig. 14. The points mark the biomass flux deduced from land use studies. This flux is equal to the negative of the rate of change of biomass and is calculated under the assumption that the carbon storage per unit area does not change with time in given land use classes. The solid line through the points represents the biomass flux derived from our solution of the differential equation for biomass evolution. The illustrated fit has been achieved by adjusting the history of biomass potential to the values plotted in the figure. Reduced biomass potential leads to reduced biomass and therefore the release of carbon dioxide from biomass. The response of biomass and the biomass flux to change in biomass potential is delayed because of the $50 \mathrm{yr}$ residence time of carbon in the biomass. This delay is incorporated into the solution of the differential equation. The results illustrated in the figure suggest that forest clearance and changing patterns of land use from uses that store more carbon per unit area to uses that store less carbon per unit area have reduced biomass potential by about $15 \%$. If all biomass were in a single kind of forest, then the area of that forest would have been reduced by $15 \%$. Alternatively if there were no further changes in land use and if the system were allowed to come to steady state, the final biomass would be $15 \%$ smaller than the initial biomass. In this calculation the initial biomass was taken to be $2 \times 10^{17}$ moles (Woodwell et al., 1983; Schlesinger, 1986). The value and the residence time of carbon in biomass are to some extent constrained by the results for radiocarbon, both the response of the system to bomb radiocarbon and to the release of fossil fuel carbon.

Inclusion of the pioneer effect has no significant impact on the history of radiocarbon in the atmosphere. Theory and observation are com. 


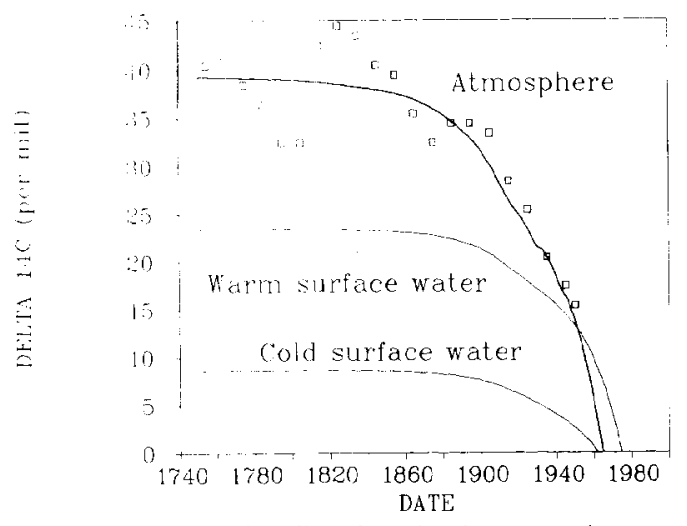

Fig. 15. Response of radiocarbon in the atmosphere and surface ocean to the release of carbon dioxide by combustion of fossil fuels and by forest clearance. Observations appear as markers, calculated values as solid lines.

pared in Fig. 15. The simulation in this case includes both fossil fuel carbon dioxide and the flux of carbon dioxide from biomass as shown in Fig. 14. Forest clearance has little effect on atmospheric radiocarbon because the difference between radiocarbon ratios in biomass and radiocarbon ratios in the atmosphere is small compared with the difference between atmosphere and fossil fuel. The difference between these two reservoirs is not great because the residence time of carbon in biomass is short compared with the decay time of radiocarbon.

The history of ${ }^{13} \mathrm{C}$ in the atmosphere is, on the other hand, significantly changed by the pioneer effect, as shown in Fig. 16. Biomass carbon is

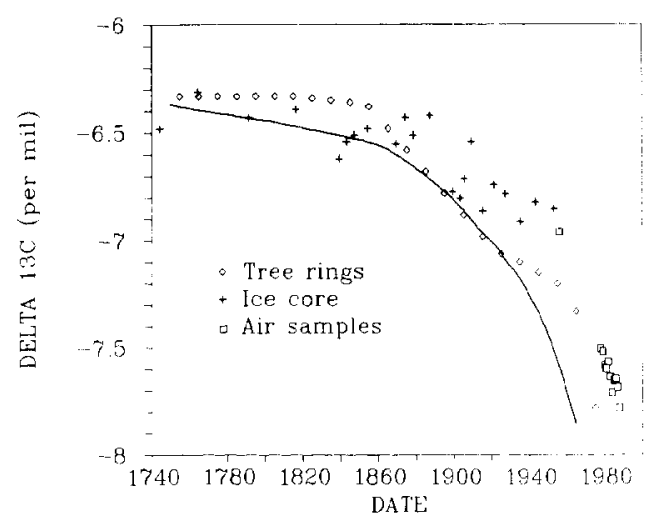

Fig. 16. Response of ${ }^{13} \mathrm{C}$ in the atmosphere to release of carbon dioxide by fossil fuel combustion and forest clearance. Observations appear as markers, theoretical values as a solid line.

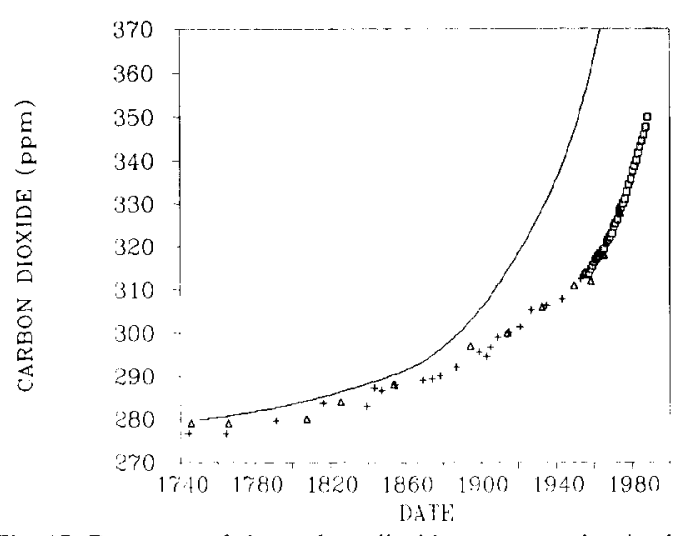

Fig. 17. Response of the carbon dioxide concentration in the atmosphere to the source provided by fossil fuel combustion and forest clearance. Observations appear as markers and the theoretical results as a solid line.

significantly lighter with respect to ${ }^{13} \mathrm{C}$ that atmospheric carbon because photosynthesis fractionates in favor of the lighter carbon isotope. Release of biomass carbon reduces the isotope ratio in the atmosphere. The agreement between theory and observation for ${ }^{13} \mathrm{C}$ is bad. The absolute values of calculated isotope ratio could be adjusted, but the amplitude of the calculated perturbation is too large.

The agreement between calculated and observed carbon dioxide mixing ratio, shown in Fig. 17 , is also bad. The simulation now includes both fossil fuel release and the pioneer effect. The agreement between theory and observation is fair until the middle of the $19^{\text {th }}$ century, but after that time the calculated carbon dioxide amounts are too large compared with observation. This result is well known in carbon cycle modelling (Enting and Pearman, 1986; Post et al., 1990). There is a missing sink for carbon dioxide.

\subsection{Fertilization}

There has been in this field a tendency for oceanographers to say that the missing sink must involve biomass and for biologists to say that the missing sink must be in the ocean. To us it appears that the data on changing land use are good and our understanding of the capacity of the ocean to adsorb carbon dioxide is good also, as evidenced by the success of this simulation in 
reproducing the history of bomb radiocarbon. In order to make progress it is necessary to guess the nature of the missing sink so that it can be incorporated into the simulation. At this point we cannot claim that our identification of the sink is better than a guess. We shall make some assumptions about the sink and proceed to work out what the consequences of those assumptions might be. The exercise provides an indication of where more research is needed. It seems to us a more profitable approach than simply pointing the finger at other people's data, measurements, and methodologies.

Specifically, we assume that the studies of the history of land use are essentially correct in the identification of changes in areas of different land use classes and so, in the usage of this simulation, in their calculation of the history of biomass potential. What we suggest is that the assumption of constant carbon storage per unit area and land use class is incorrect because of the fertilization effect of carbon dioxide. For purpose of this simulation we shall assume that the growth rate of biomass is proportional not only to biomass potential but also increases with the partial pressure of carbon dioxide. In this way, even as the area of more carbon-rich biomes decreases, the carbon storage per unit area increases with increasing atmospheric carbon dioxide, so total global biomass does not decline as fast. Keeling et al. (1989b) and Esser (1987) have also ascribed the missing sink to carbon dioxide fertilization, which may be the cause of the increasing amplitude of seasonal change in carbon dioxide (Bacastrow et al., 1985; Houghton, 1987).

For the functional dependence of growth rate on carbon dioxide we adapt the expression of Esser (1987), derived from ecological and physiological data

$F_{\mathrm{Bio}}=C_{\mathrm{Bio}} B_{\mathrm{p}} F\left(\mathrm{CO}_{2}\right)$

where $C_{\mathrm{Bi}}=2 \times 10^{17}$ moles is the equilibrium value of biomass for carbon dioxide mixing ratio $=280 \mathrm{ppm}$ and biomass potential $B_{\mathrm{P}}=1$. Here

$F\left(\mathrm{CO}_{2}\right)=2.22\left(1-\exp \left[-0.003\left(p \mathrm{CO}_{2}-80\right)\right]\right)$

with $\mathrm{pCO}_{2}$ expressed in ppm. The fertilization function is plotted in Fig. 18. This fertilization

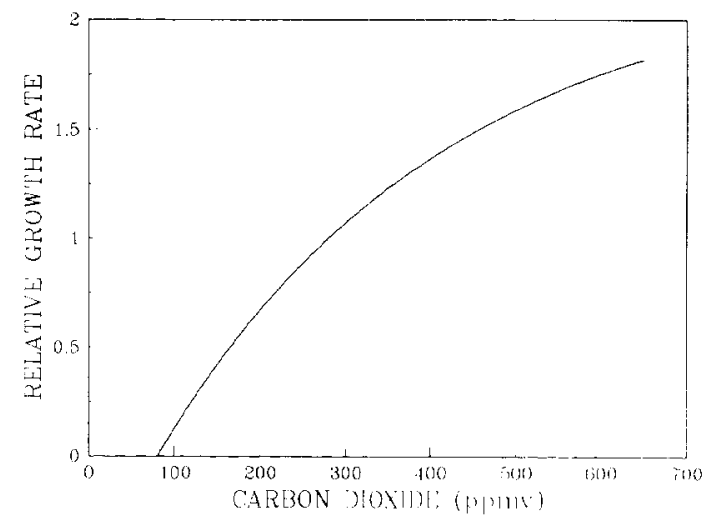

Fig. 18. Assumed fertilization function. The figure shows how the global rate of photosynthesis is assumed to depend on the carbon dioxide concentration in the atmosphere.

function yields reasonable agreement between calculated and observed carbon dioxide mixing ratios, as shown in Fig. 19.

It is, moreover, consistent with the characterization of the missing sink by Tans et al. (1990). From careful observational and theoretical studies of the meridional gradient in carbon dioxide amount these authors were able to establish the approximate magnitude of the missing sink in the early years of the 1980 's as between 2 and $3 \times 10^{14}$ $\mathrm{m} / \mathrm{y}$, and its location as being in middle to high latitudes of the Northern Hemisphere. This Northern Hemisphere location is consistent with our identification of the missing sink as associated with biomass because the Northern Hemi-

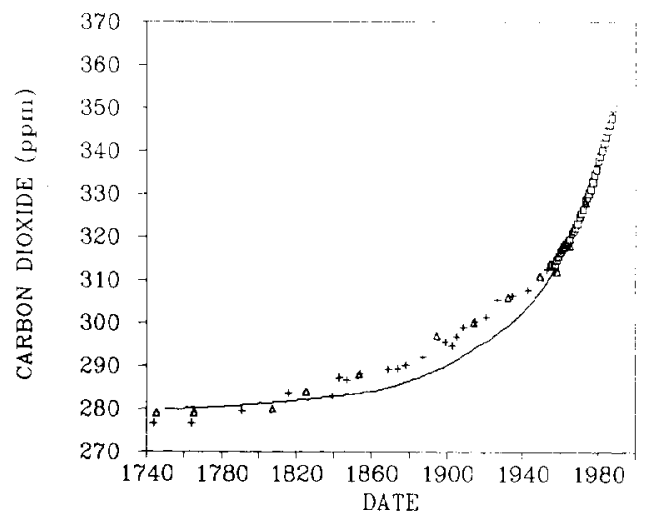

Fig. 19. Response of atmospheric carbon dioxide concentration to the release of carbon dioxide by fossil fuel combustion and forest clearance with the assumption of carbon dioxide fertilization of the global rate of photosynthesis. Observations appear as markers and the theoretical results as a solid line. 


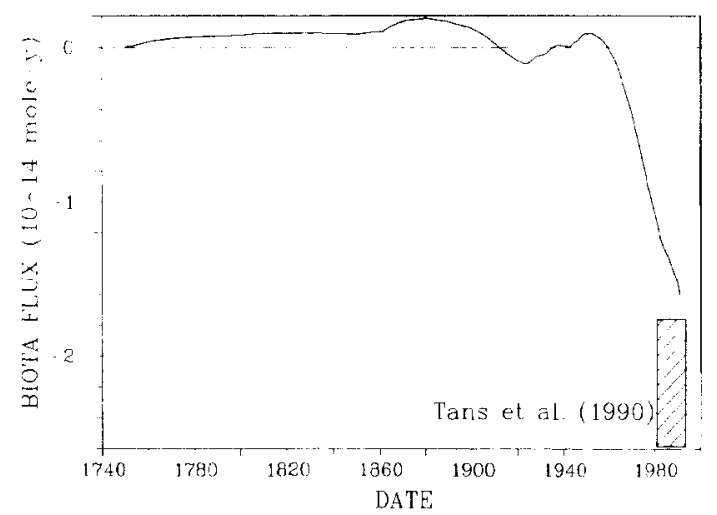

Fig. 20. The derived flux of carbon from biomass to atmosphere plotted as a solid line, and an estimate of this flux derived from observations of latitudinal gradients in carbon dioxide concentration, plotted as a rectangle. The calculated flux represents the combined effects of land use change and carbon dioxide fertilization of the rate of photosynthesis.

sphere is where most middle to high latitude biomass is located. Moreover, the magnitude of the missing sink deduced by Tans et al. is reasonably consistent with the deductions of our simulation with the fertilization assumption. Fig. 20 shows the biomass flux calculated in the simulation with biomass potential as shown in Fig. 14, but with carbon dioxide fertilization. With these assumptions there was little change in biomass until about 1950. Increase in biomass due to the fertilization effect of increasing carbon dioxide has just about cancelled decrease caused by forest clearance, represented here by decreasing biomass potential. Since about 1950 , the fertilization effect has dominated over the clearance effect, global biomass has been increasing, and the biota has been absorbing carbon dioxide.

Because carbon dioxide has increased by about $25 \%$ in the last century our assumption of a fertilization effect almost proportional to carbon dioxide implies an increase in stored carbon per unit area of a comparable $25 \%$. We are not aware of any observations that could rule out such a change. Carbon concentrations quoted for each land use class generally vary by as much as a factor of 2 or 3 , reflecting variability within the class. There is no way to say that these numbers have not increased by $25 \%$ in the last century.
Looked at in another way, if we suppose that most of the biomass is in the form of trees, and that the mass of carbon in the tree varies as the cube of the height of a tree we are looking at an increase in the height of the average mature tree by just $8 \%$ in a century. [Actually, the diameter of a tree must increase more rapidly than the height to prevent buckling, so the height increase is less than $8 \%$ (T. Volk, private commun., 1991). On the other hand it may be that increased height would lead to increased spacing between trees (K. Caldeira, private commun., 1991). Such a change can not be ruled out on the basis of observation.

As already noted, biomass changes have little effect on the radiocarbon content of the atmosphere so the agreement between theory and observation shown in Fig. 21 is good in this case as in the previous cases. Results for the case carbon isotopes are shown in Fig. 22. The agreement in this case is worse than in the case of fossil fuel only (Fig. 12), particularly in the comparison with direct measurements in the last decade or so. The biota is isotopically light. As it increases in mass it drives the atmosphere isotopically heavy. The calculated ${ }^{13} \mathrm{C}$ amounts for the recent past are larger than the observed.

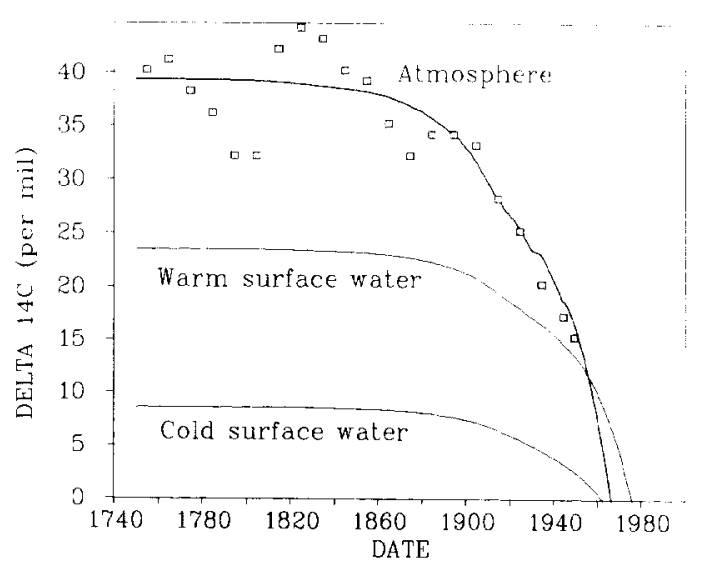

Fig. 21. Response of radiocarbon in atmosphere and surface ocean to the release of carbon dioxide from fossil fuel combustion and forest clearance, with allowance for carbon dioxide fertilization of the global rate of photosynthesis. Observations appear as markers and the calculated values as solid lines. 


\subsection{Agriculture and isotopes}

We have now developed a simulation that reasonably reproduces bomb radiocarbon data, the pre-industrial state in the ocean, atmospheric carbon dioxide, and radiocarbon during the industrial revolution. There is a remaining problem of substantial disagreement between calculated and observed ratios of atmospheric ${ }^{13} \mathrm{C}$. For the sake of neatness we make a further speculative suggestion about a possible resolution of the ${ }^{13} \mathrm{C}$ discrepancy.

Some plants, the $\mathrm{C} 3$ type, fractionate carbon by $20 \%$ during the course of photosynthesis. Other plants, the C4 type, fractionate by only 6\% (Van der Merwe, 1982). Among the C4 plants are such important agricultural types as maize and sugar cane. Is it possible that during the course of changing patterns of agricultural and land use there has been a change in the global ratio of $\mathrm{C} 3$ plants to $\mathrm{C} 4$ plants that has resulted in a change in biomass fractionation with respect to atmospheric carbon isotopes?

In order to explore this possibility we have repeated the calculation that includes fossil fuel burning, land use change, and carbon dioxide fertilization with the introduction of a change in carbon isotope fractionation during the course of photosynthesis. Specifically the expression we

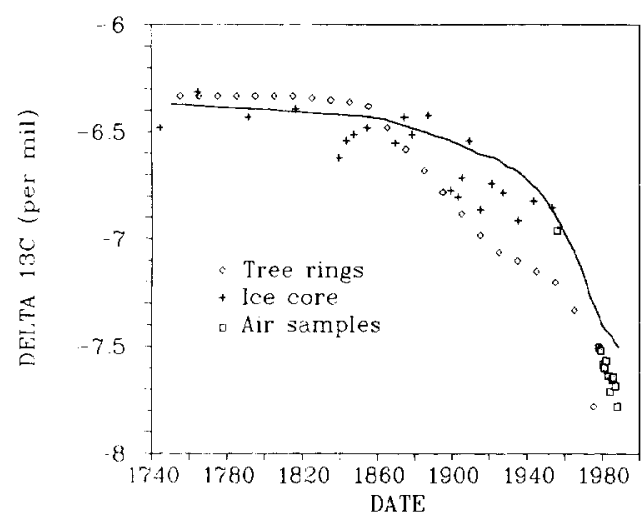

Fig. 22. Response of ${ }^{13} \mathrm{C}$ in the atmosphere to the release of carbon dioxide by fossil fuel combustion and forest clearance, with allowance for carbon dioxide fertilization of the global rate of photosynthesis. Observations appear as markers and the theoretical results as a solid line.

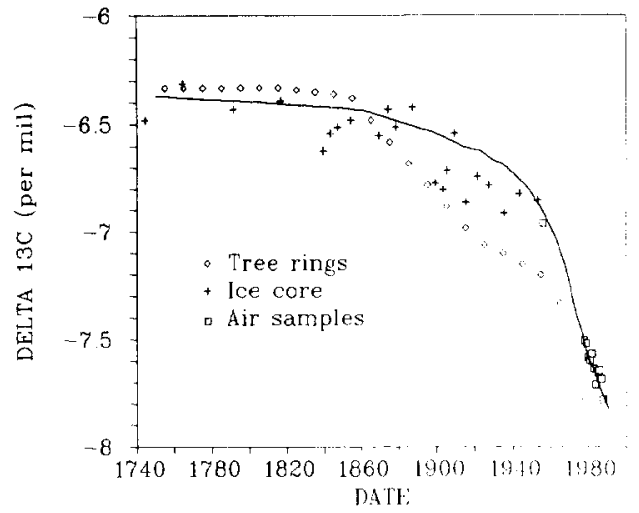

Fig. 23. Response of atmospheric ${ }^{13} \mathrm{C}$ to the release of carbon dioxide by fossil fuel combustion and forest clearance, with allowance for carbon dioxide fertilization of the global rate of photosynthesis and a small change in the global average carbon fractionation in photosynthesis associated with an agricultural shift from $\mathrm{C} 3$ plants to $\mathrm{C} 4$ plants

have used for the fractionation factor in photosynthesis is

$\Delta_{\text {phot }}(\% \circ)=20-f(t)$

where $f(t)=0$ before 1960 and increases linearly from 0 in 1960 to 0.84 in 1990. The amplitude of the change is tuned to reproduce the observed carbon isotope history. Theory and observations are compared in Fig. 23. With this further assumption, the agreement between theory and observation is as good for ${ }^{13} \mathrm{C}$ as for ${ }^{14} \mathrm{C}$ and carbon dioxide partial pressure. The remaining discrepancy in the late 1800's and early 1900's for carbon dioxide could be removed by adjusting the fertilization function. Adjustments to the assumed history of photosynthetic fractionation could alter the fit for $\delta^{1.3} \mathrm{C}$. Both of these functions are otherwise unconstrained.

Is this a reasonable resolution of the ${ }^{13} \mathrm{C}$ problem? It is hard to say. The required change in the fractionation factor associated with global productivity is only $4 \%$, corresponding to a replacement of only $6 \%$ of $\mathrm{C} 3$ photosynthesis by $\mathrm{C} 4$ photosynthesis. We are not talking about a very large replacement of $\mathrm{C} 3$ plants by $\mathrm{C} 4$ plants. Perhaps such a change has occurred.

The rest of this paper does not depend on our suggestion concerning the influence of agriculture on carbon isotopes. The calculation just presented serves mainly to call attention to a factor 
that may have affected the observation record of atmospheric ${ }^{13} \mathrm{C}$ and to show the limited diagnostic power of the carbon isotope records.

\section{Extrapolation}

The simulation has now been tuned to the steady state distributions of dissolved phosphorus, total dissolved carbon, and carbon isotopes in the oceanic reservoirs and to the history of bomb radiocarbon. The tuned simulation has been tested and further modified to reproduce the industrial age history of atmospheric carbon dioxide, radiocarbon, and stable carbon isotopes. In this section we shall use the simulation without further modification to explore possible extrapolations of carbon dioxide evolution into the future. The approach is to assume scenarios for fossil fuel burning and for forest clearance and to calculate the evolution of atmospheric carbon dioxide in response to these various scenarios. This process is not correctly described as prediction, because the calculated carbon dioxide levels depend entirely on the assumed scenarios, and we make no effort to justify the scenarios. Ideally, different components of a prediction system would be used to develop scenarios for carbon dioxide release in response to changes in global population, climate, and technology. The use of assumed scenarios enables us to explore some options for the future and to find out what control measures might most effectively influence future levels of carbon dioxide. The simulation is a tool for exploring possible consequences of future courses of action, not a tool for predicting the future.

We consider limiting scenarios for fossil fuel combustion and for forest clearance. These scenarios are illustrated in Fig. 24. The two fossil fuel scenarios both consume the same total reserve of recoverable fossil fuel, $35 \times 10^{16}$ moles (Broecker and Peng, 1982). The profligate scenario assumes that the rate of consumption of fossil fuel continues to increase until the reserves begin to run out in a hundred years or so. There follows a turnaround and a rapid decrease in the rate of consumption of fossil fuel, with the reserve exhausted before 2400 A.D. This scenario is

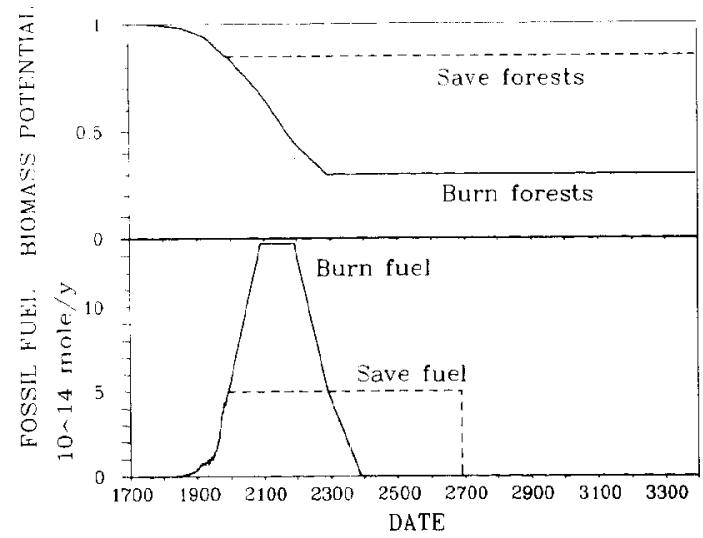

Fig. 24. Scenarios for the consumption of a fixed fossil fuel reserve and for the destruction of global biomass.

labeled "burn fuel" in Fig. 24. It is similar to the scenarios shown in Fig. 1 except that the peak burning rate is only three times the present value, as compared to five times this value, and the total amount of carbon consumed is slightly smaller. For the austere scenario, labeled "save fuel" in Fig. 24, we assume that the rate of combustion of fossil fuel is held constant at its present day value $\left(5 \times 10^{14} \mathrm{~m} / \mathrm{y}\right)$ until the reserve is exhausted in $700 \mathrm{yr}$ time. The fossil fuel combustion rate drops to zero shortly before 2700 A.D. These scenarios seem to us to more or less encompass the range of possibilities, subject to a fixed total reserve of fossil fuel. For forest clearance, the austere scenario, labelled "save forests" in Fig. 24, assumes no further reduction of biomass potential from that of the present day. This scenario implies an immediate end to the clearance of forest and the conversion of land from uses sustaining high carbon content per unit area to uses sustaining lower carbon content. The profligate scenario, labelled "burn forests" in Fig. 24 assumes that land use changes and forest clearance continue at about the present rate until biomass potential has been reduced to 0.35 of its value in 2300 A.D., remaining constant at that value into the future. Again, we view these scenarios as more or less bounding the range of possible future changes in land use.

We are particularly interested in extrapolations on a time scale of centuries to millennia, a time scale that has received little recent attention. Exploration of the possible consequences of 


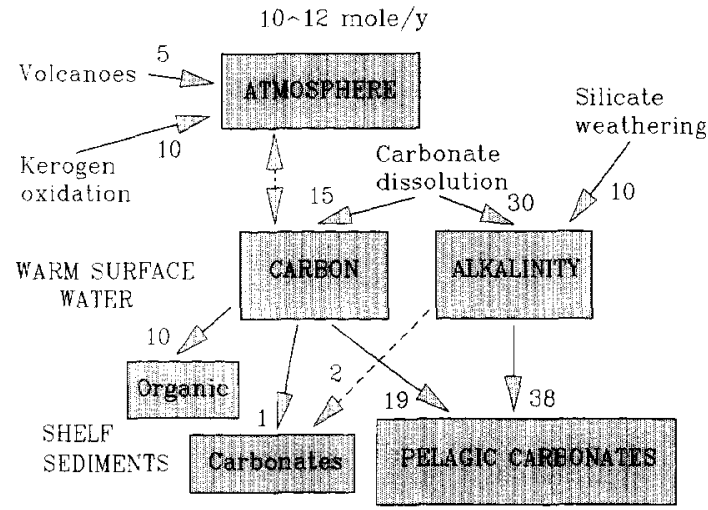

Fig. 25. The rock cycle, showing values of fluxes used in this simulation. Fluxes are expressed in units of $10^{12}$ moles per year.

global change on a time scale of several generations is most definitely needed. On the longer time scale, however, the rock cycle begins to influence the results. We shall therefore first describe our formulation of the rock cycle and test the sensitivity of simulated carbon dioxide levels to the description of the rock cycle. We shall then explore the possible responses of atmospheric carbon dioxide to the various scenarios for fossil fuel burning and forest clearance.

\subsection{Rock cycle}

Our formulation of the rock cycle is derived fairly directly from the work of Walker et al. (1981), Berner et al. (1983), Kasting et al. (1986), and other references. The components are illustrated in Fig. 25. Carbon dioxide is released to the atmosphere by volcanic and metamorphic processes at a constant rate of $5 \times 10^{12} \mathrm{~m} / \mathrm{y}$ $\left(1 / 100\right.$ of the present rate of $\mathrm{CO}_{2}$ release from fossil fuel burning). This carbon dioxide is neutralized by the weathering of silicate minerals, which releases calcium and magnesium ions to the warm surface water reservoir at a rate that we take to depend on the carbon dioxide partial pressure, a dependence that includes possible dependences on temperature and runoff (Walker et al., 1981; Berner et al., 1983). Possible dependences on vegetation (Volk, 1989b) are not included in this study. The calcium and magnesium ions and the volcanic carbon dioxide are ultimately removed from the system by precipitation as carbonate minerals. Further weathering reactions dissolve terrestrial carbonate rocks, adding alkalinity and total dissolved carbon to the warm surface water reservoir at a rate that depends on the carbon dioxide partial pressure. In this formulation there is an additional source of atmospheric carbon dioxide provided by the oxidation of sedimentary organic carbon, called kerogen. The rate of this oxidation process is $10^{13} \mathrm{~m} / \mathrm{y}$. It is exactly balanced in our formulation by the precipitation of fresh organic carbon in shelf sediments (Berner, 1982), although short-term imbalances are possible in the real world.

Most accumulation of carbonate sediments occurs in the deep sea, according to the formulation described above. The rain of carbonate particles into the deep sea is proportional to planktonic productivity, which depends on the flux of dissolved phosphate into the warm surface water reservoir. Carbonate particles which fall below the lysocline dissolve while those that fall into shallower waters are preserved. The rain of particulate carbonate is assumed to be spatially uniform. Lysocline depth is proportional to the carbonate ion concentration in each deep ocean reservoir. The fraction of area of each ocean above the lysocline is based on observed average ocean hypsometry. We include a small flux of carbonate to the shallow shelves at a rate proportional to the carbonate ion concentration in warm surface sea water. This flux is given by $10^{12}\left[\mathrm{CO}_{3}^{2-}\right] / 0.26$ mole $/ y$, with $\left[\mathrm{CO}_{3}^{2-}\right]$ expressed in moles $/ \mathrm{m}^{3}$ (Wilkinson and Walker, 1989). In the steady state, the total carbonate flux is 20 times larger.

As previous work has shown, the key element in the rock cycle is how the carbonate and silicate dissolution rates depend on carbon dioxide partial pressure. In the very long term it is this dependence that determines the steady state partial pressure of carbon dioxide in the atmosphere. In the shorter term it is this dependence that determines how quickly the system of ocean and atmosphere will recover from the impulsive input of fossil fuel carbon dioxide. Various formulations of the weathering rate laws have been pro- 
posed by Walker et al. (1981), Berner et al. (1983), and Volk (1987). In our view, all of these rate laws are subject to very serious uncertainty. On the other hand, the weathering rate law controls the carbon dioxide response only on a time scale of thousands to millions of years and so is not at the heart of the current study. For simplicity, we shall not include in our formulation an explicit dependence of weathering rates on the hydrologic cycle or on global average temperature, expressing the weathering rates simply as functions of carbon dioxide partial pressure. The expressions we use are $W_{\text {carb }}=15 \times 10^{12} \mathrm{pO}_{2}$ and $W_{\text {sil }}=5 \times 10^{12}\left(p \mathrm{CO}_{2}\right)^{0.3}$ moles $/ \mathrm{y}$, with $p \mathrm{CO}_{2}$ expressed in PAL. The silicate weathering law is based on laboratory data cited by Walker et al. (1981). The rate at $p \mathrm{CO}_{2}=1 \mathrm{PAL}$ is set equal to the assumed volcanic outgassing rate. (These two rates must be in balance at steady state.) Its dependence on $p \mathrm{CO}_{2}$ is intermediate between that of Walker et al. (1981) and Berner et al. (1983). Carbonate weathering is assumed to have a stronger dependence on $\mathrm{pCO}_{2}$; this choice is made so as to maximize potential $\mathrm{CO}_{2}$ uptake by this process. In the next section we show how modification of these expressions affects the calculated levels of carbon dioxide.

The steady state values of carbon isotope ratios in ocean and atmosphere depend on the isotope ratios associated with the sources and sinks of carbon in the rock cycle. The values we use are as follows: volcanoes, -0.7 ; kerogen oxidation, -22.3; carbonate dissolution, 1.7 ; new organic carbon fractionated by $-25 \%$; new carbonates fractionated by $+1.7 \%$. These values have been tuned, with only modest observational constraints, to yield the steady state isotopic composition of ocean and atmosphere that gave the results of Fig. 8.

\subsection{Dissolution of pelagic carbonate sediments}

As fossil fuel carbon dioxide moves into the deep ocean the waters become more corrosive, the lysocline moves to shallower depths, and previously deposited pelagic carbonate sediments become susceptible to dissolution. Dissolution of these sediments adds alkalinity and total dis-

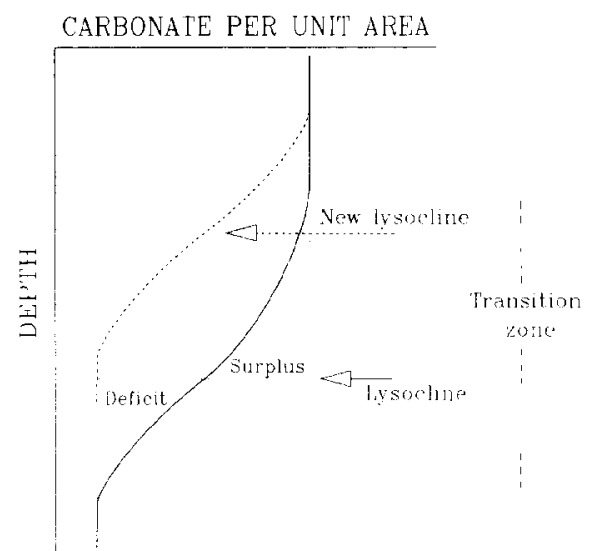

Fig. 26. The carbonate transition zone in pelagic sediments is represented in this calculation by a sudden change in dissolution rate, with no carbonate dissolution occurring above the lysocline and complete dissolution occurring below the lysocline.

solved carbon to the deep sea reservoirs, increasing their capacity to absorb the added carbon dioxide. In this section we describe how this process is represented in our simulation. In developing this representation we have sought an upper limit on the role of pelagic carbonate dissolution by assuming rapid reaction of a large mass. We can test the sensitivity of our results to pelagic carbonate dissolution by suppressing the process completely.

We treat our calculated lysocline depth as marking a sharp transition between shallower levels in which no carbonate dissolution occurs and deeper levels in which no carbonate accumulation takes place. The actual transition in the real ocean is more gradual as shown schematically in Fig. 26. In terms of the total carbonate accumulation rate, our step function representation incurs a deficit by ignoring accumulation below the calculated lysocline depth, but incurs a balancing surplus by neglecting dissolution above the calculated lysocline depth.

Suppose now that the lysocline moves to a shallower depth, as indicated by the dashed lines in Fig. 26. Carbonate sediments at depths between the new transition and the old transition become subject to dissolution. The total mass of carbonate that might be dissolved is given by the area of sea floor between the new lysocline depth and the old lysocline depth multiplied by the 
mass of soluble carbonate sediment per unit area. This total mass can be represented with little error by the step function distribution of carbonate accumulation rate because the areas of accumulation surplus just balance the areas of accumulation deficit. Following Broecker and Peng (1982) we assume that all of the carbonate minerals in the top $30 \mathrm{~cm}$ of sediment are susceptible to dissolution. If the carbonate sediments consist of one-third insoluble clay minerals, on average, dissolution of $30 \mathrm{~cm}$ of sediment will build up a $10 \mathrm{~cm}$ thick layer of clay which should halt further dissolution. The carbonate content of the top $30 \mathrm{~cm}$ of sediment is taken to be 6000 moles $/ \mathrm{m}^{2}$. We regard this as a generous estimate of the amount of calcium carbonate that is likely to dissolve.

From the rate of change of total dissolved carbon and alkalinity in the deep ocean reservoirs we calculate the rate of change of the carbonate ion concentration. From the rate of change of carbonate ion concentration we calculate the rate of change of lysocline depth, using the linear relationship between lysocline depth and carbonate ion concentration. From the rate of change of the lysocline depth we calculate the rate of change of ocean area above the lysocline, using observed average ocean hypsometry. This rate of change of ocean area above the lysocline is multiplied by 6000 moles $/ \mathrm{m}^{2}$ to get the rate at which pelagic carbonate minerals are added to a reservoir of dissolving pelagic carbonate sediments. There is one such reservoir of dissolving pelagic carbonate sediments for each deep ocean basin. These sediments dissolve according to a first order rate law, with a dissolution time of $10 \mathrm{yr}$. On a time scale of decades to centuries, therefore, the dissolution of pelagic carbonates is effectively instantaneous. Rapid reaction is assumed in order to maximize the potential impact of this process. The dissolution of these pelagic carbonates adds alkalinity and total dissolved carbon to the appropriate deep ocean reservoirs.

When the lysocline moves to greater depths there is a corresponding extraction of alkalinity and total dissolved carbon from the deep ocean reservoirs. To see this, consider the transition shown in Fig. 26 between the shallow lysocline indicated by dashed lines and the deeper lysocline indicated by solid lines. When the lysocline moves to deeper levels the transition region where carbonate dissolution is partial has to be filled with the appropriate stock of carbonate minerals before the step function representation of carbonate accumulation rate can be considered a reasonable approximation. The filling of this transition zone to bring the deficit accumulation region back into balance with the surplus accumulation region extracts total dissolved carbon and alkalinity from the deep ocean reservoir. The rate of extraction is the 6000 moles $/ \mathrm{m}^{2}$ of available carbonate times the rate of increase of area of the sea floor bathed by saturated sea water. The process is symmetrical. Movement of the lysocline to shallower depths exposes previously deposited carbonate sediments in the transition zone to dissolution, releasing carbon and alkalinity to the sea water. Movement of the lysocline to greater depths causes a reduction in the dissolution of carbonate particles that fall into the transition zone, effectively extracting carbon and alkalinity from the sea water. Our formulation deals with changes in lysocline depth either upward or downward. We have sought an upper limit on the role of pelagic carbonate dissolution. We now show the effect of suppressing this process completely.

\subsection{Sensitivity to the rock cycle}

For the sensitivity test we adopt as standard a profligate scenario in which fossil fuel and forests are both burned. The evolution of carbon dioxide partial pressure to the year 5000 A.D. is shown by the solid line in Fig. 27. In this scenario carbon dioxide increases to almost 2200 parts per million before fossil fuel reserves are exhausted in about the year 2400 A.D. Thereafter, the carbon dioxide partial pressure decreases as the added carbon dioxide is transferred into the deep ocean and is gradually neutralized by weathering reactions.

We test the sensitivity of the result to pelagic carbonate dissolution by suppressing the process altogether. The results are shown by the dashed line in Fig. 27. They are indistinguishable from 


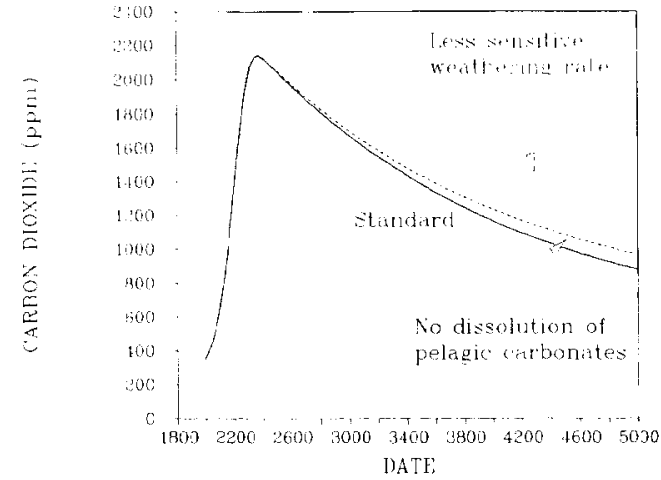

Fig. 27. Sensitivity of carbon dioxide predictions to the formulation of the rock cycle. These results correspond to a profligate scenario in which both fossil fuel and forests are rapidly burned. If dissolution of pelagic carbonates is suppressed in the simulation, there is a modest increase in carbon dioxide concentrations a few thousand years in the future. Results are more sensitive to assumptions concerning the dependence of carbonate weathering rate on carbon dioxide partial pressure, but even this process has little effect on carbon dioxide prior to the maximum in about the year 2400 .

the standard run until after the maximum in carbon dioxide partial pressure at about 2400 A.D. Thereafter, the suppression of pelagic carbonate dissolution results in higher carbon dioxide partial pressures, as would be expected. Pelagic carbonate dissolution has virtually no influence on the result in the first few hundred years of the simulation because the thermohaline circulation takes hundreds of years to carry the extra carbon dioxide into the deep ocean reservoirs. In this formulation we deliberately separated the deep ocean reservoir into separate Atlantic, Indian, and Pacific Ocean basins in order to see whether more rapid ventilation of the Atlantic Ocean might have a more immediate effect on carbon dioxide levels. However, the residence time of water in our deep Atlantic reservoir, calculated by dividing the volume of the reservoir by the influx of water from the cold surface water reservoir is still $690 \mathrm{yr}$, as shown in Fig. 3. It takes this long for the saturation state of this reservoir to change significantly in response to changes in the atmosphere. The process could be carried further, by sub-dividing the deep Atlantic reservoir into a north Atlantic reservoir with still more rapid ventilation and a south Atlantic reservoir with a longer residence time, but the carbonate sediments available for dissolution in such a north Atlantic deep reservoir would not be very abundant. We conclude that dissolution of pelagic carbonates is not likely to influence the levels of atmospheric carbon dioxide before sev. eral hundred years have elapsed. The main conclusions of this paper, which concern maximum carbon dioxide concentrations, are not sensitive to our formulation of the pelagic dissolution process.

On the other hand, the influence of dissolution of pelagic carbonates on lysocline depth is profound, as would be expected. The evolution of lysocline depths in the standard run and in the run pelagic dissolution suppressed is shown in Fig. 28. The figure shows how the carbon dioxide perturbation is felt first in the Atlantic Ocean and last in the Pacific Ocean and how the response of lysocline depth is very much larger in the simulation in which pelagic carbonate dissolution is suppressed. By releasing alkalinity to the deep ocean reservoirs, pelagic carbonate dissolution serves to neutralize the effect of fossil fuel carbon dioxide, limiting the amplitude of excursions in lysocline depth. By overestimating the dissolution of pelagic carbonates, our simulation underestimates changes in both lysocline depth and carbon dioxide partial pressure. We regard

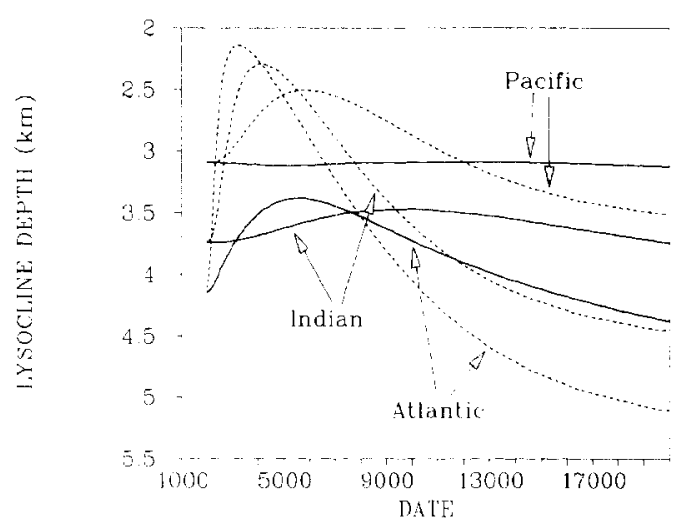

Fig. 28. The effect on lysocline depths of pelagic carbon dissolution. These results are for the same profligate scenario as Fig. 27. The solid lines show the evolution of lysocline depths in the different ocean basins in the standard run. If pelagic carbonate dissolution is suppressed, changes in lysocline depth are much more pronounced, as shown by the dashed lines. 
this as a conservative treatment of unavoidable uncertainties.

Also shown in Fig. 27 are results that illustrate the sensitivity of carbon dioxide partial pressure to the weathering rate law. For purposes of this comparison, the carbonate weathering rate was taken to be proportional to the square root of carbon dioxide partial pressure instead of the first power, and the silicate weathering rate was left unchanged, proportional to the carbon dioxide partial pressure raised to the power of 0.3 . This change in the weathering rate law has no significant impact on calculated carbon dioxide levels prior to about 2200 A.D. Thereafter, reduced weathering fluxes result in larger carbon dioxide pressures.

The relative buffering capacities of terrestrial carbonate weathering and pelagic carbonate dissolution depend on poorly quantified weathering and dissolution rate laws. Because we have assumed that the rate of weathering of terrestrial carbonates is directly proportional to $p \mathrm{CO}_{2}$, this rate is increased by a factor of six in our standard run at the time of the carbon dioxide maximum. This corresponds to a very large flux of alkalinity to the ocean, some $2 \times 10^{14}$ equivalents/year. Moreover, the rate of terrestrial weathering responds immediately to carbon dioxide changes, but pelagic carbonate dissolution is delayed by the ventilation time of the deep sea. Our calculation suggests that terrestrial carbonate weathering may be more important than previously thought, but is also suggests that more work is needed to determine the probable response of this process to future carbon dioxide increases.

The long-term recovery of this system is controlled by the rock cycle. Figure 29 shows the long-term evolution of atmospheric carbon dioxide, comparing the cases with modified weathering rate and without pelagic carbonate dissolution, and shows also the evolution of lysocline depths in the standard case. The time scale here is logarithmic because such a scale best shows the changes that occur on short time scales initially and then on the very much longer time scales associated with the rock cycle. What we see here is that the carbon dioxide content of the atmosphere continues to increase as long as fossil fuel

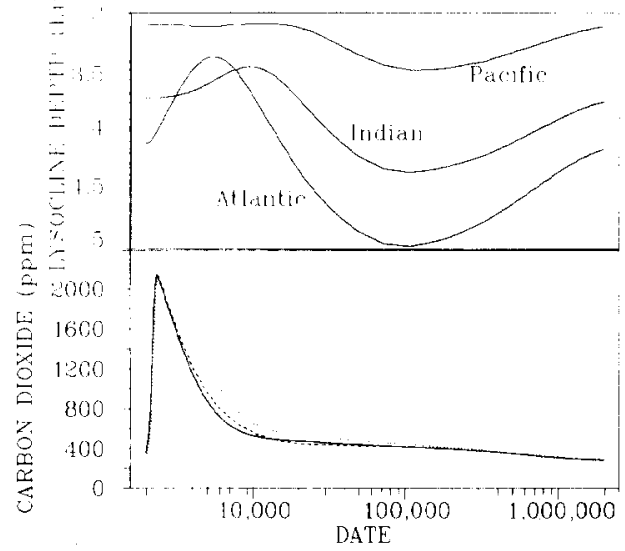

Fig. 29. The long term recovery of atmospheric carbon dioxide after the injected of fossil fuel and forest carbon dioxide according to the profligate scenario. The different lines in the carbon dioxide plot correspond to the standard scenario, plotted as a solid line. the case with pelagic carbonate dissolution suppressed, plotted as a dashed line, and the case with reduced sensitivity to carbon dioxide pressurc of the carbonate weathering rate, plotted as a dotted line. The evolution of lysocline depths in the standard case is plotted at the top of the figure. The time scale is logarithmic. Complete recovery takes more than a million years.

is being burned. The accessible reservoirs, biomass, and surface ocean, are too small to absorb the added carbon dioxide, which mostly accumulates in the atmosphere. The large deep ocean reservoirs are not accessible on the time scale of a few hundred years associated with exhaustion of the fossil fuel reserve. Atmospheric carbon dioxide begins to decrease as soon as fossil fuel combustion has ended. This decrease is fast at first as the deep ocean comes to equilibrium with surface ocean and atmospheric reservoirs. There follows a much slower recovery associated with the gradual neutralization of the added carbon dioxide by rock weathering. It has not generally been realized how long the fossil fuel perturbation may last. The duration, of course, depends on the weathering rate law, but an indication of the time for recovery can be obtained by dividing the total fossil fuel reserve, $3.5 \times 10^{17}$ moles by the expected enhancement in silicate weathering rate. If silicate weathering varies as the carbon dioxide partial pressure raised to the power of 0.3 then a doubling of carbon dioxide partial pressure will increase the silicate 


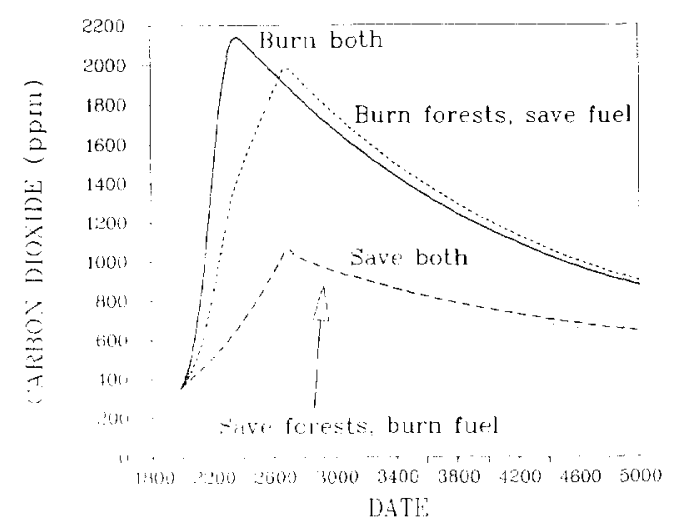

Fig. 30. Responses of atmospheric carbon dioxide to the various scenarios for fossil fuel combustion and forest clearance. These results correspond to the assumption of carbon dioxide fertilization of the global rate of photosynthesis.

weathering rate by a factor of $2^{0.3}$ for an augmentation in the rate of about $1 \times 10^{12}$ moles $/ y$. Such an augmented rate would require $350,000 \mathrm{yr}$ to neutralize the total fossil fuel release. The recovery will be more rapid if the increase in weathering rate with carbon dioxide partial pressure is more marked.

\subsection{Sensiticity of carbon dioxide to fuel and forest scenarios}

All of the calculations of this section are begun in 1990 A.D. with the values calculated in the section on the industrial revolution and run into the future for a few million years. We consider four scenarios for fuel and forest burning, as described above, and illustrated in Fig. 24. Results for the carbon dioxide partial pressure over a few thousand years are shown in Fig. 30. The solid line shows the results already presented in which both fuel and forests are burned rapidly. Carbon dioxide partial pressure peaks at almost 2200 parts per million a little before the year 2400 A.D. If fuel is conserved while forests are burned, the maximum carbon dioxide concentration is reduced only to about 2000 parts per million, but the maximum is postponed to about the year 2700 A.D. It is at this time that the fossil fuel reserve is exhausted under the "save fuel" scenario.
In this calculation, saving the forests leads to a marked reduction in the maximum carbon dioxide partial pressure, to about 1100 parts per million or just 3 times the present level. This reduction results from the fertilization effect and the absorption of fossil fuel carbon dioxide by the preserved forests. The point can be seen most clearly in Fig. 31, which illustrates the evolution of biomass for these various scenarios. In the "save forest" scenarios biomass increases from its present value by almost a factor of 2 . When forests are burned, an initial increase in biomass corresponding to the fertilization effect is soon overwhelmed by forest clearance, so both fuel burning and forest burning contribute to the calculated increase in atmospheric carbon dioxide.

In both the forest burn and the forest save cases, the maximum carbon dioxide partial pressure occurs at the time of exhaustion of the fossil fuel reserve. This is because fossil fuel combustion rates are much greater than any of the geochemical rates in this system. Oceans and rocks cannot absorb the carbon dioxide as fast as it is being added. It simply accumulates in the atmosphere and biota until the fossil fuel reserve is exhausted. For the same reason, the maximum value of the carbon dioxide partial pressure is relatively insensitive to the rate at which fossil fuels are burned. In the time scale for exhaustion of the fossil fuel reserve, $700 \mathrm{yr}$ in our austere scenario, very little of the added carbon dioxide

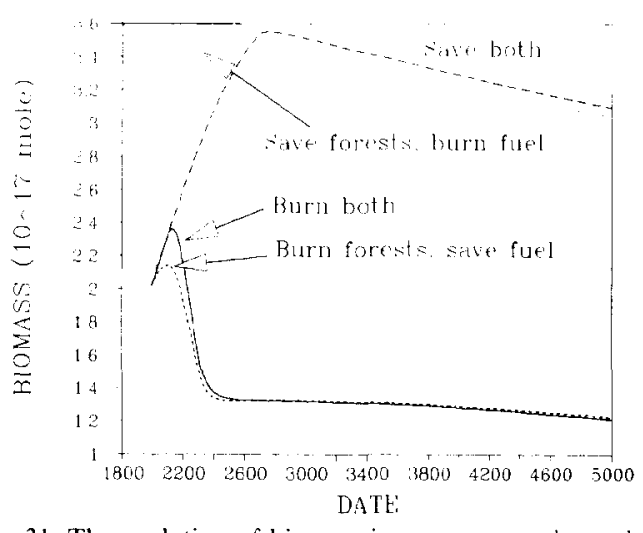

Fig. 31. The evolution of biomass in response to the various scenarios for fossil fuel combustion and forest clearance. The results correspond to the carbon dioxide results of Fig. 30 . 
can be absorbed by the deep ocean. The maximum value of carbon dioxide partial pressure depends mainly on the total amount of fossil fuel carbon dioxide released and only weakly on the rate of release. Energy conservation can delay the occurrence of large carbon dioxide partial pressures, but those large pressures will finally arrive unless the fossil fuel is left in the ground.

On the other hand, this simulation suggests that we might be able to substantially limit future increases in atmospheric carbon dioxide by preserving global biomass. This conclusion depends directly on our assumption of a significant enhancement in plant growth rate caused by carbon dioxide increases-an idea that has been suggested numerous times before (e.g. Revelle and Munk, 1977; Freyer, 1979, refs. on p. 90). This assumption has been criticized (Bolin et al., 1979; Houghton and Woodwell, 1989) because it does not include any possibly unfavorable impact of climate change on biomass or, more specifically, on carbon storage in soils. In this sense the "save forest" calculations shown in Fig, 30 may be wildly optimistic. They do serve, however, to call attention to the potential importance of biomass as a sink for fossil fuel carbon dioxide and suggest that conservation of biomass may be as important to the limitation of global change as conservation of fossil fuel.

\subsection{Sensitivity to biomass growth and decay rates}

In order to explore the sensitivity of the results to assumptions made about rates of growth and decay of the biomass we have conducted some further calculations. For purposes of the sensitivity study we use the scenario in which forests are preserved at their present biomass potential but fossil fuel is rapidly consumed. This is the "save forests, burn fuel" scenario of Fig. 24. The standard simulation, for which results have already been presented, appears in Figs. 32 and 33 as the "enhanced growth, constant decay" case. Enhanced growth refers to the fertilization of biomass growth rate by carbon dioxide. Constant decay refers to the residence time of carbon in biomass and soils, in this case assumed constant at $50 \mathrm{yr}$.

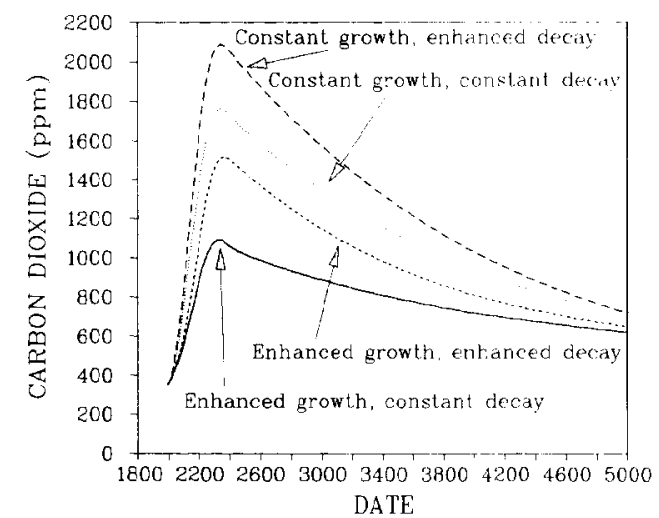

Fig. 32. Sensitivity of future levels of carbon dioxide to assumptions about biomass changes. These results correspond to the scenario in which fossil fuel is rapidly burned, but forests are conserved. The standard run includes dioxide fertilization, but no increase in biomass decay rate in response to increases in global average temperature. Comparative runs show the effect of increasing rates of biomass decay and the suppression of the carbon dioxide fertilization effect.

In order to explore the sensitivity of the results to assumptions made about rates of growth and decay of the biomass we have conducted some further calculations. For purposes of the sensitivity study we use the scenario in which forests are preserved at their present biomass potential but fossil fuel is rapidly consumed. This is the "save forests, burn fuel" scenario of Fig. 24. The standard simulation, for which results have already been presented, appears in Figs. 32 and 33 as the "enhanced growth, constant decay" case. En-

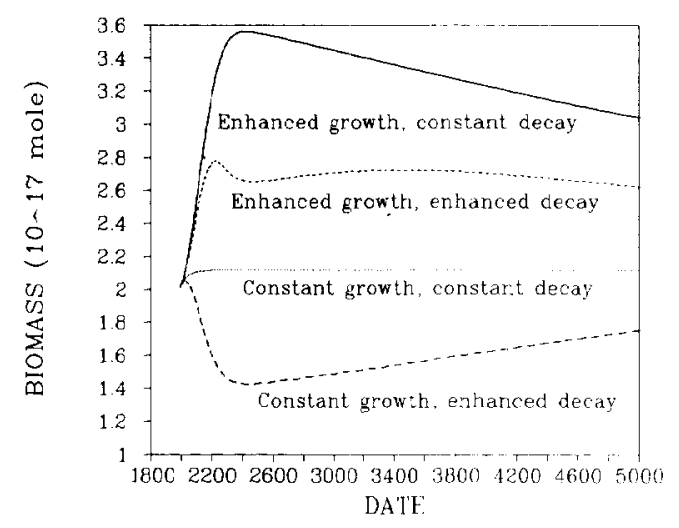

Fig. 33. Sensitivity of biomass changes in response to various assumptions concerning growth rates and decay rates. These results for biomass correspond to the results for carbon dioxide concentration in Fig. 32. 
hanced growth refers to the fertilization of biomass growth rate by carbon dioxide. Constant decay refers to the residence time of carbon in biomass and soils, in this case assumed constant at $50 \mathrm{yr}$.

The results presented for comparison in Figs. 32 and 33 are for cases in which biomass growth rate is held constant at its 1990 value. There is no further carbon dioxide fertilization and no further change in biomass potential. This is referred to as the "constant growth" case. The "enhanced decay" case is one in which the residence time of carbon in biomass is reduced by a factor of 2 for an increase of global average temperature by $10^{\circ} \mathrm{C}$. Our energy balance climate model yields rather modest increases in global average temperature up to a maximum of about $6^{\circ} \mathrm{C}$. We assume that the biomass decay rate is a linearly increasing function of global average temperature. The "constant growth, enhanced decay" case yields maximum carbon dioxide concentrations about twice those of the "enhanced growth, constant decay" case (see Fig. 32). The other cases are intermediate. Corresponding changes in biomass appear in Fig. 33.

The lesson to be drawn here is that there is no guarantee that forest conservation will indeed lead to dramatic reductions in future atmospheric carbon dioxide levels. The terrestrial biota appear to have been absorbing $\mathrm{CO}_{2}$ during the past half century, but may cease to do so as the climate warms. From a policy standpoint, we should attempt to preserve the forests but we should not assume that doing so will protect us from the extremely high atmospheric $\mathrm{CO}_{2}$ levels predicted in our worst case scenarios or by studies like those shown in Fig. 1. The important role of biomass in our standard simulation is a direct consequence of our assumption of a large fertilization effect.

\subsection{Towards a sustainable economy}

As a tentative exploration of a possible goal we consider in this section whether it might be possible by rigorous energy conservation measures to hold the partial pressure of atmospheric carbon dioxide permanently below 500 parts per million

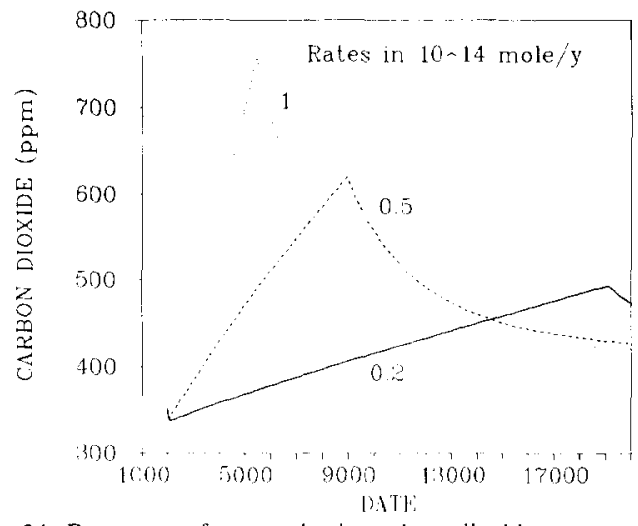

Fig. 34. Response of atmospheric carbon dioxide concentrations to various constant rates of fossil fuel combustion. These results assume that forest clearance is immediately halted and that the total fossil fuel reserve is consumed at the constant rate indicated on the figure. The present rate of fossil fuel combustion is $5 \times 10^{14}$ moles per year. These results indicate that an immediate reduction in fossil fuel combustion by a factor of 25 would hold carbon dioxide concentrations below 500 parts per million.

while still exhausting our fossil fuel reserves. For purposes of this calculation we assume an immediate end to forest clearance, holding biomass potential constant at its present value of 0.85 , and we use the (most favorable) "enhanced growth, constant decay" model. We assume an immediate reduction in the rate of fossil fuel combustion to various levels smaller than the present level, holding this rate constant until the reserve is exhausted. The results appear in Fig. 34. They show that sustainability in this sense could be achieved if the fossil fuel combustion rate were permanently reduced from its present level of $5 \times 10^{14}$ $\mathrm{m} / \mathrm{y}$ to $0.2 \times 10^{14} \mathrm{~m} / \mathrm{y}-\mathrm{a}$ reduction by a factor of 25 , not the factor of 2 that is sometimes quoted in the press. Since the assumptions made in doing this calculation are optimistic to begin with, we conclude that keeping atmospheric $\mathrm{CO}_{2}$ levels below $500 \mathrm{ppm}$ would probably require switching to alternative energy sources long before our fossil fuel reserves are depleted.

\section{Conclusion}

In this study we have put together a simple numerical simulation of the global biogeochemical cycles affecting atmospheric carbon dioxide. 
We have worked with the smallest number of reservoirs and the simplest formulation that seemed able to reproduce reasonably well the observations that relate to this problem and also to represent the processes likely to be important on the time scales of decades to millenia of principal interest to us. We have adjusted the parameters of our simulation to reproduce such observations as the distribution of phosphate and total dissolved carbon between ocean reservoirs, the isotope ratios for both ${ }^{13} \mathrm{C}$ and ${ }^{14} \mathrm{C}$ in ocean and atmosphere, and the histories of carbon dioxide partial pressure and isotope ratios through the $19^{\text {th }}$ and $20^{\text {th }}$ centuries, including the response of radiocarbon to its production by atomic weapons tests. With this tuned simulation we have calculated future levels of atmospheric carbon dioxide for various assumed scenarios concerning the future course of fossil fuel burning and land use change, including forest clearance. This does not constitute a prediction of future levels of carbon dioxide but, rather, a tentative look at how those levels might respond to various changes in human practice. The goal of our study has been to provide an indication of what possible courses of action might be fruitful and what issues merit further study. The major conclusions are not particularly sensitive to the details of our simulation.

\section{Appendix}

This appendix presents the equations, expressions, and parameters used in the simulation. We present these expressions in the form of annotated computer code, in the belief that anyone who uses these expressions will use them in a computer program and because presentation in this form minimizes the chance of errors in transcription.

\section{DEFINITIONS}

The dependent variables are designated $y(i)$. Their time derivatives are yp(i).

$\mathrm{pco2}=\mathrm{y}(1)$

pcs $=y(2)$

pad $=y(3)$

pid $=y(4)$

ppd $=y(5)$

$\mathrm{ptc}=\mathrm{y}(6)$

cws $=y(7)$

$\operatorname{ccs}=y(8)$

$\mathrm{cad}=\mathrm{y}(9)$

$\operatorname{cid}=y(10)$

$\mathrm{cpd}=\mathrm{y}(11)$

ctc $=y(12)$

aws $=y(13)$

acs $=y(14)$

$\mathrm{aad}=\mathrm{y}(15)$

aid $=y(16)$

$\mathrm{apd}=\mathrm{y}(17)$

atc $=y(18)$

acalc $=y(19)$

icalc $=y(20)$

pcalc $=y(21)$

tbar $=y(22)$

drat $=y(23)$

drws $=y(24)$

dres $=\mathrm{y}(25)$

$\mathrm{drad}=\mathrm{y}(26)$

$\mathrm{drid}=\mathrm{y}(27)$

$\mathrm{drpd}=\mathrm{y}(28)$

$d r t c=y(29)$

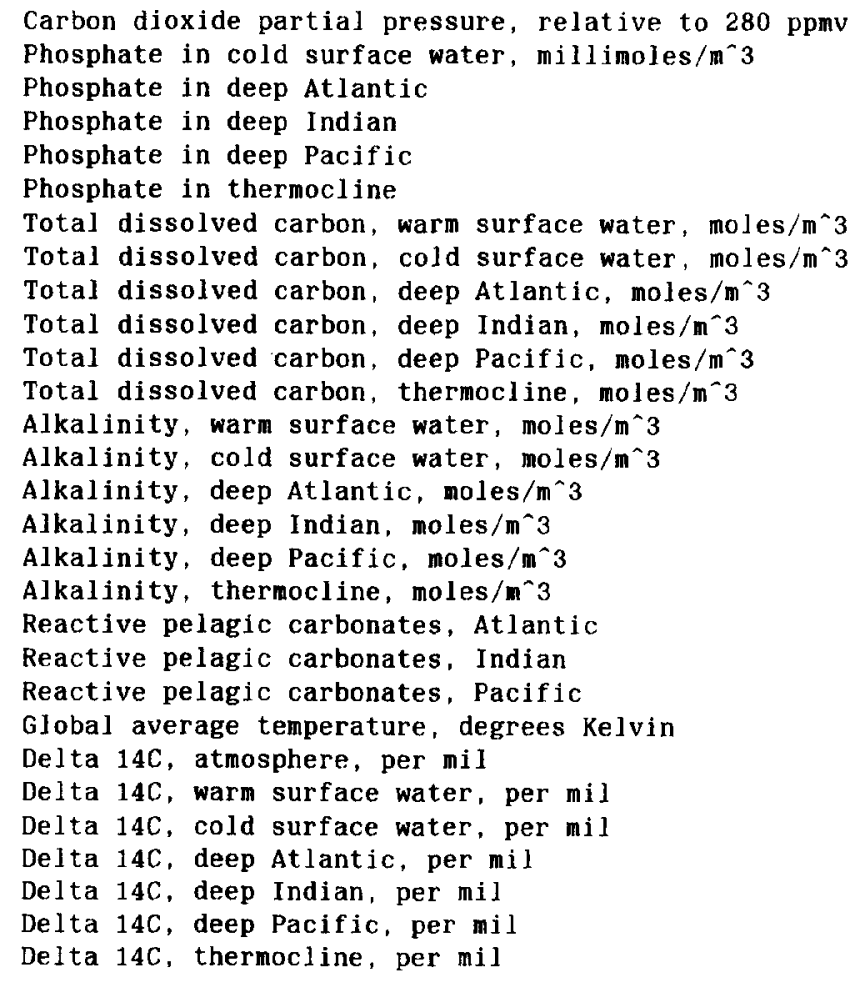




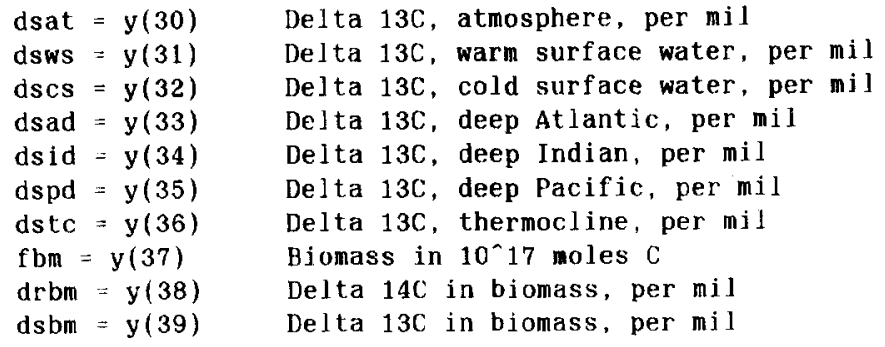

\section{DIFFERENTIAL EQUATIONS}

Carbon dioxide

$y p(1)=($ pco2ws - pco2 $) *(1$ careaf $r)+($ pcozes - pcoz $) *$ careaf $r$

$y p(1)=y p(1) /$ distime $+($ volc + kerox + fue $l+$ forest $)$ / matmco 2

Phosphorus

yp(2) $=\operatorname{mwscs} *$ (pws - pcs) $+\operatorname{mtccs} *(p t c-p c s)+f t c c s *$ (ptc - pcs)

$\mathrm{yp}(2)=\mathrm{yp}(2) / \mathrm{vcs}$

$y p(3)=(f \operatorname{csad} *($ pcs - pad $)+\operatorname{mtcad} *($ ptc - pad $)+$ addecay $/$ ctpr $) /$ vad

yp $(4)=($ fadid $*($ pad - pid $)+m t c i d *(p t c-$ pid $)+$ iddecay $/$ ctpr $) /$ vid

$\operatorname{yp}(5)=($ fidpd $*($ pid - ppd $)+m t c p d *(p t c-p p d)+$ pddecay $/$ ctpr $) /$ vpd

$y p(6)=$ fadtc $*$ pad + fidtc * pid + fpdtc * ppd - ftccs* ptc

$y p(6)=y p(6)+\operatorname{mtccs} *(p c s-p t c)+\operatorname{mtcad} *($ pad $\cdots$ ptc)

$y p(6)=y p(6)+m t c i d *(p i d-p t c)+m t c p d *(p p d-p t c)$

yp $(6)=(y p(6)+$ mtcws $*($ pws - ptc $)+$ tcdecay $/$ ctpr $) /$ vtc

Total dissolved carbon

yp $(7)=\operatorname{mwscs} *(\operatorname{ccs}-\operatorname{cws})+\operatorname{mtcws} *(\operatorname{ctc}-\operatorname{cws})-\operatorname{prod} *(1+\operatorname{corat})$

$\mathrm{yp}(7)=\mathrm{yp}(7)+(\mathrm{pco} 2-\mathrm{pco} 2 \mathrm{ws}) /$ distime $*$ matmco $2 *(1-$ careaf $r)$

$y p(7)=(y p(7)+$ carbw - shcarb shcorg $) /$ vws

yp $(8)=\operatorname{mwscs} *($ cws $-\operatorname{ccs})+\operatorname{mtccs} *(\operatorname{ctc}-\operatorname{ccs})+\mathrm{ftccs} *(\operatorname{ctc}-\operatorname{ccs})$

$y p(8)=(y p(8)+(p c o 2-$ pco2cs $) /$ djstime * matmco2 * careaf $) /$ vcs

$y p(9)=f \operatorname{csad} *(\operatorname{ccs}-\operatorname{cad})+$ addecay

yp $(9)=(y p(9)+$ prod * corat * adarea / darea * $(1$ - afroa $)+$ acdr $) /$ vad

$y p(10)=$ fadid $*($ cad - cid $)+$ iddecay

$\mathrm{yp}(10)=(\mathrm{yp}(10)+$ prod $*$ corat $*$ idarea $/$ darea $*(1 \cdots$ ifroa $)+$ icdr $) /$ vid

yp $(11)=$ fidpd $*($ cid - cpd $)+$ pddecay

$\mathrm{yp}(11)=(\mathrm{yp}(11)+\operatorname{prod} *$ corat $*$ pdarea $/$ darea $*(1-$ pfroa $)+$ pcdr $) / \mathrm{vpd}$

$y p(12)=$ fadtc $*$ cad + fidtc $*$ cid + fpdtc * cpd - ftces * ctc

$y p(12)=y p(12)+m t c c s *(\operatorname{ccs}-\operatorname{ctc})$

$\mathrm{yp}(12)=(\mathrm{yp}(12)+\mathrm{mtcws} *(\mathrm{cws}-\mathrm{ctc})+\mathrm{tcdecay}) / \mathrm{vtc}$

Alkalinity

$y p(13)=\operatorname{mwscs} *($ acs - aws $)+m t c w s *($ atc $\cdots$ aws $)-\operatorname{prod} *(2 *$ corat -.15$)$

$y p(13)=(\operatorname{yp}(13)+2 *($ carbw + silw - shcarb $)) /$ vws

yp(14) $=$ mwscs $*($ aws - acs $)+m t c c s *(a t c-a c s)+f t c c s *$ (atc: acs)

$\operatorname{yp}(14)=(\operatorname{yp}(14)) / \operatorname{vcs}$

$y p(15)=f \operatorname{csad} *($ acs - aad $)+$ addecay $*(-.15)$

$\mathrm{yp}(15)=\left(\operatorname{yp}(15)+2 *\left(\right.\right.$ prod $* \operatorname{corat}^{*}$ adarea $/$ darea $*(1-$ afroa $\left.\left.)+\operatorname{acdr}\right)\right) /$

vad

$y p(16)=$ fadid $*($ aad - aid $)+$ iddecay $*(-.15\}$

$\operatorname{yp}(16)=(\operatorname{yp}(16)+2 *(\operatorname{prod} *$ corat $*$ idarea $/$ darea $*(1-$ ifroa $)+$ icdr $))$

vid

$\operatorname{yp}(17)=$ fidpd $*($ aid - apd $)+$ pddecay $*(-.15)$

$y p(17)=\left(y p(17)+2 *\left(\operatorname{prod} * \operatorname{corat}^{*}\right.\right.$ pdarea $/$ darea $*(1-$ pfroa $)+$ pcdr $\left.)\right) /$

vpd

$y p(18)=$ fadtc $*$ aad + fidtc $*$ aid + fpdtc $*$ apd $-f t c c s *$ atc

$\mathrm{yp}(18)=\mathrm{yp}(18)+\mathrm{mtccs} *(\mathrm{acs} \cdot \mathrm{atc})$

$y p(18)=\left(y p(18)+m_{t c w s} *(\right.$ aws - atc $)+$ tcdecay $\left.*(-.15)\right) /$ vtc

Pelagic carbonates

$y p(19)=-a c d r+a l s r$

$y p(20)=-i c d r+i l s r$

$\mathrm{yp}(21)=-$ pcdr + plsr 


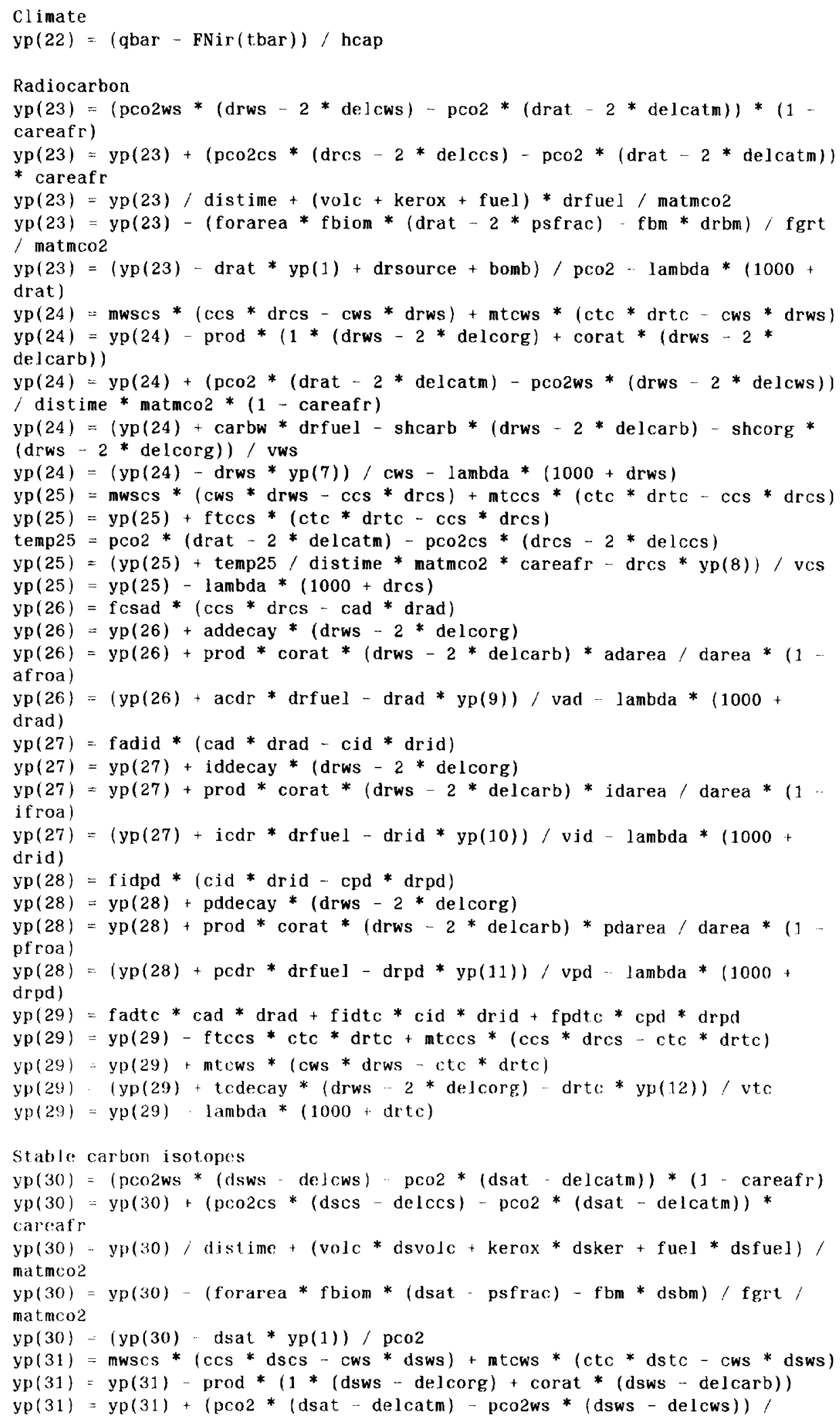




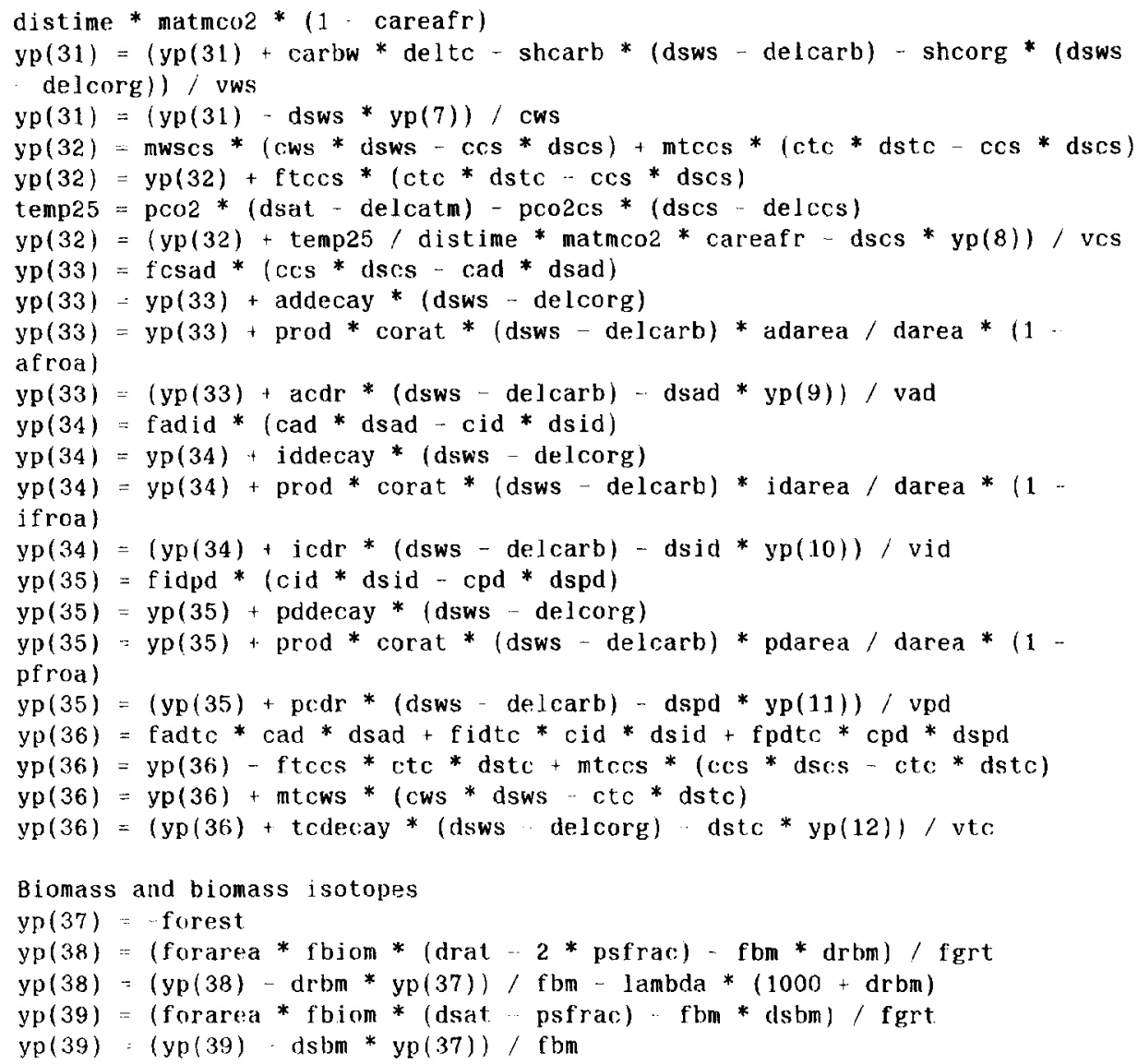

\section{SPECIFIED FUNCTIONS OF TIME}

fuel Fossil fuel combustion rate in $10^{\prime \prime} 17$ moles $/ y$

dsfuel Delta $13 \mathrm{C}$ in fossil fuel, per mil

forarea Biomass potential

psfrac Average 13C fractionation in photosynthesis

bomb Radiocarbon production from nuclear weapons tests

\section{DERIVED VARIABLES}

Phosphorus in warm surface water, millimoles $/ \mathrm{m}^{\wedge} 3$ :

pws $=$ pfp $*$ ppd

Biological productivity:

prod $=\operatorname{mwscs} *($ pcs - pws $)+$ ntcws $*(p t c-p w s)$

prod $=($ prod + rivp - shphos $*$ pws $) *$ ctpr

Phosphorus mineralization in thermocline and deep ocean reservoirs:

tcdecay $=$ prod $*$ tcpfrac

addecay $=\operatorname{prod} *(1-$ tcpfrac $) *$ adarea $/$ darea

iddecay $=$ prod $*(1-$ tcpfrac $) *$ idarea $/$ darea

pddecay $=$ prod $*(1-$ tcpfrac $) *$ pdarea $/$ darea

Dissolution of pelagic carbonates:

acdr $=$ acalc $/ \mathrm{cdt}$

icdr $=$ icalc $/ \mathrm{cdt}$

pcdr $=$ pcalc $/$ cdt 
Fertilization of biomass growth:

fert $=2.22 *(1-\operatorname{EXP}(-.003 *(280 * \operatorname{pco} 2-80)))$

fbiom $=$ fbiomz $*$ fert

Biomass respiration dependence on temperature:

fgrt $=$ fgrtz $/(1+($ tbar -288.262$) / 10)$

forest $=$-forarea $*$ fbiom $/$ fgrtz + fbm $/$ fgrt

Weathering rates:

carbw $=$ carbwz $*$ pco2

silw $=$ silwz $*$ pco2 $* 3$

Stable carbon isotope fractionation, per mil:

delcws $=9.5-($ tws -298$) / 10 \quad$ Warm water to atmosphere

delccs $=9.5 \cdot(\operatorname{tcs}-298) / 10 \quad$ Cold water to atmosphere

delcatm $=1.6 \quad$ Atmosphere to water

Radiation coefficients depence on carbon dioxide:

ira $=$ iraz $+9.56 *$ LOG $(p c o 2)$

$\mathrm{irb}=\mathrm{irbz}-.0514 * \operatorname{LOG}(\mathrm{pco} 2)$

Long-wave flux:

FNir(tbar) = ira $+i r b *$ tbar

Shelf carbonates:

shcarb :=.00001* co3ws / .26

Warm water temperature:

tws $=\left(\right.$ tbar - careaf $r^{*}$ tcs $) /(1 \cdots$ careaf $r)$

\section{CARBONATE RELATIONSHIPS}

Carbonate equilibria:

kcarb $=.000575+.000006 *$ (watemp -278 ) watemp is water temperature

$\mathrm{kco2}=.035+.0019 *($ watemp -278$)$

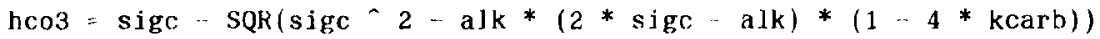

hco3 $=$ hco3 $/(1-4 *$ kcarb $)$

$\cos =(a l k-h \cos ) / 2$

pco2s $=k \operatorname{co} 2 * \mathrm{hco3}^{\wedge} 2 / \operatorname{co} 3 \quad$ equilibrium c02 pressure

Lysocline depth and fractional area above lysocline:

lydp $=$ lycon $1+$ lycon $2 *(\cos -.1) \quad$ Must exceed 0

froa $=.1+(1 \mathrm{ydp} / 6) \sim 2.5 \quad$ Must not exceed 1

Additions to deep-sea carbonate reservoir:

dsigc is rate of change of sigc

dalk is rate of change of alkalinity

dhco3, dco3, dlydp, dfroa are also rates of change

dtemp is a temporary variable

dtemp $=$ dalk* $(2 *$ sigc - alk $)+$ alk* $(2 *$ dsigc - dalk $)$

dtemp $=2^{*}$ sigc $*$ dsigc - dtemp $*\left(1-4^{*}\right.$ kcarb $)$

dhco3 $=.5 / \operatorname{SQR}\left(\operatorname{sigc}{ }^{*} 2-\operatorname{alk} *(2 * \operatorname{sigc}-\operatorname{alk}) *(1-4 * k \operatorname{kcarb})\right)$

dhco3 $=$ (dsigc - dhco3 $*$ dtemp) $/\left(1-4^{*}\right.$ kcarb $)$

$\mathrm{dco3}=(\mathrm{dalk}-\mathrm{dhco3}) / 2$

dlydp $=1 y \operatorname{con} 2 *$ dco 3

dfroa $=2.5 / 6 *(1 y d p / 6) * 1.5 *$ dlydp

alsr, ilsr, plsr are additions to reactive carbonate reservoirs calculated

from:

dcar $=-6 *$ dfroa $*$ oparea $\quad 10^{\wedge} 17 \mathrm{moles}$

where oparea is the appropriate ocean area 


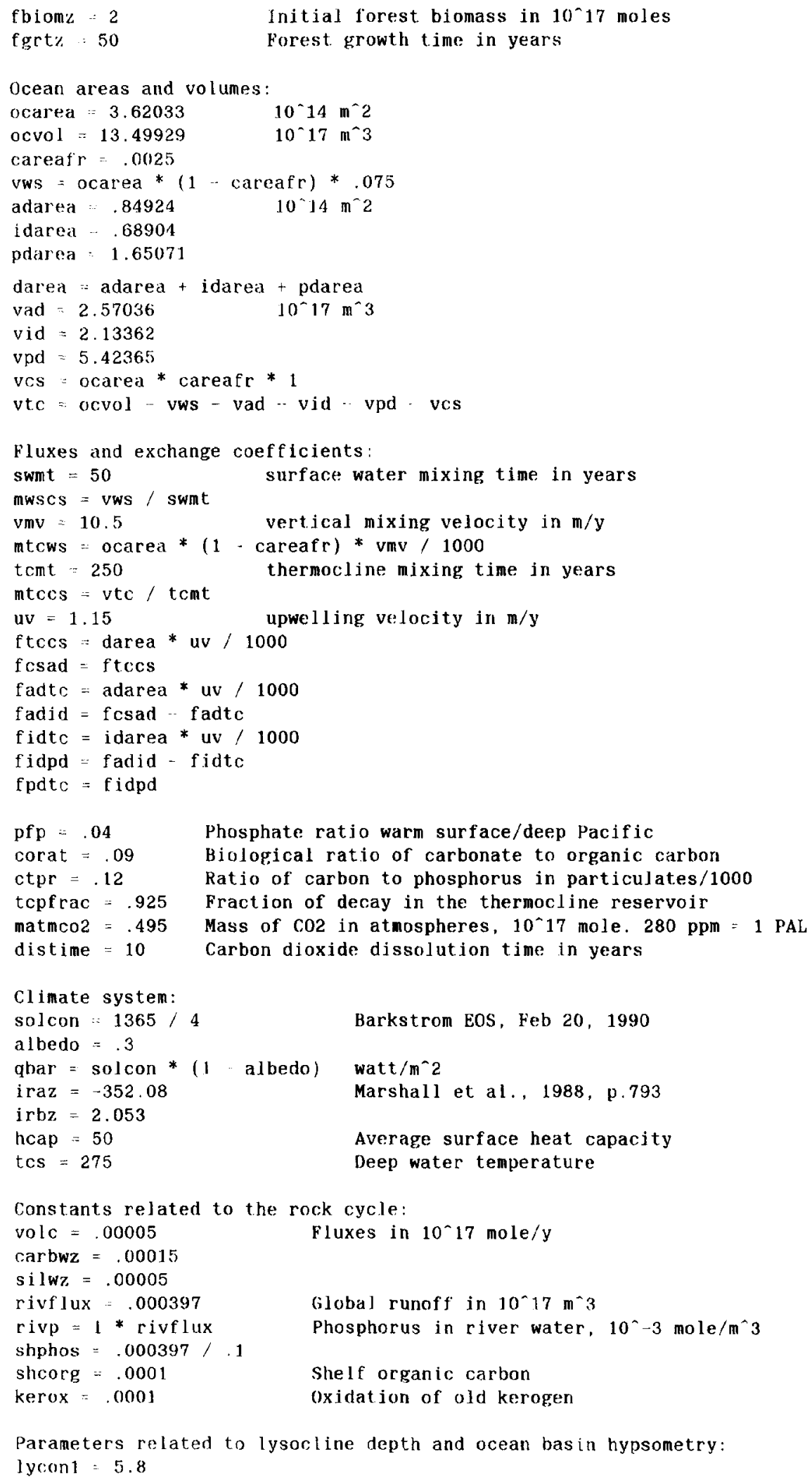




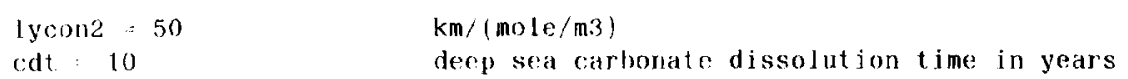

Constants related to isotopes:

$\begin{array}{ll}\text { delcorg }=25 & \text { Fractionation by phytoplankton, per mil } \\ \text { deltc }=1.32 & \text { Isotope ratio in CARBW } \\ \text { dsvolc }=-.7 & \text { Carbon } 13 \text { in volcanic gases } \\ \text { dsker }=-22.3 & \text { Carbon } 13 \text { in kerogen } \\ \text { delcarb }=1.7 & \text { Fractjonation in carbonate precipitation } \\ \text { drfuel }=-1000 & \text { Radiocarbon in fossil fuel } \\ \text { lambda }=1 / 8267 & \text { Radiocarbon decay constant per year } \\ \text { drsource }=4.29 & \text { Effective atmospheric source of radiocarbon } \\ & \text { Multiply drsource by } 118 \text { to get global moles } / y\end{array}$

\section{References}

Anderson, T.F. and Arthur. M.A., 1983. Stable isotopes of oxygen and carbon and their application to sedimentological and paleoenvironmental problems. In: M.A. Arthur (Editor), Stable Isotopes in Sedimentary Geology. SEPM Course No. 10, Soc. Econ. Paleontol. Mineral., Tulsa, Okla., pp. 1.1-1.151.

Bacastrow, R.B. and Bjorkstrom, A., 1981. Comparison of ocean models for the carbon cycle. In: B. Bolin (Editor), Carbon Cycle Modelling, SCOPE 16 Wiley, New York, pp. 29-79.

Bacastrow, R.B., Keeling, C.D. and Whorf, T.P., 1985. Seasonal amplitude increase in atmospheric $\mathrm{CO}_{2}$ concentration at Mauna Loa, Hawaii, 1959-1982. J. Geophys. Res., 90: 10529-10540.

Berner, R.A., 1982. Burial of organic carbon and pyrite in the modern ocean: Its geochemical and environmental significance. Am. J. Sci., 282: 451-473.

Berner, R.A., Lasaga, A.C. and Garrels, R.M., 1983. The carbonate-silicate geochemical cycle and its effect on atmospheric carbon dioxide over the past 100 million years. Am. J. Sci., 283: 641-683.

Bolin, B., Degens, E.T., Duvigneaud, P. and Kempe, S., 1979. Carbon Cycle Modelling. In: B. Bolin, E.T. Degens, S. Kempe and P. Ketner (Editors), The Global Carbon Cycle, SCOPE Rept. 13. Wiley, New York, pp. 1-28.

Broecker, W.S. and Peng, T.-H., 1982. Tracers in the Sea. Lamont-Doherty Geological Observatory, Palisades, New York, $690 \mathrm{pp}$.

Detwiler, R.P. and Hall, C.A.S., 1988. Tropical forests and the global carbon cycle. Science, 239: 42-47.

Enting. I.G. and Pearman, G.I., 1986. The use of observations in calibrating and validating carbon cycle models. In: J.R. Trabalka and D.E. Reichle (Editors), The Changing Carbon Cycle: A Global Analysis. Springer, New York, pp. $425-458$.

Esser, G., 1987. Sensitivity of global carbon cycle pools and fluxes to human and potential climatic impacts. Tellus, 39B: $245-260$.

Freyer, H.-D., 1979. Variations in the atmospheric $\mathrm{CO}_{2}$ content. In: B. Bolin, E.T. Degens, S. Kempe and P. Ketner (Editors), The Global Carbon Cycle: A Global Analysis. Scope 13. Wiley, New York, pp. 79-100.
Freyer, H.D., 1986. Interpretation of the Northern Hemispheric record of ${ }^{13} \mathrm{C} /{ }^{12} \mathrm{C}$ trends of atmospheric $\mathrm{CO}_{2}$ in tree rings. In: J.R. Trabalka and D.E. Reichle (Editors), The Changing Carbon Cycle: A Global Analysis. Springer, New York, pp. 125-150.

Friedli, H., Lotscher, H., Oeschger, H., Siegenthaler, U. and Stauffer, B., 1986. Ice core record of the ${ }^{13} \mathrm{C} /{ }^{12} \mathrm{C}$ ratio of atmospheric $\mathrm{CO}_{2}$ in the past two centuries. Nature, 324: $237-238$.

Gordon, A.L., 1986. Interocean exchange of thermocline water. J. Geophys. Res., 91: 5037-5046.

Goudrian, J., 1989. Modelling biospheric control of carbon fluxes between atmosphere, ocean, and land in view of climatic change. In: A. Berger, S. Schneider and J.C. Duplessy (Editors), Climate and Geo-Sciences. Kluwer Academic Publishers, Boston, pp. 481-499.

Hobbie, J., Cole, J., Dungan, J., Houghton, R.A. and Peterson. B., 1984. Role of the biota in global $\mathrm{CO}_{2}$ balance: The controversy. BioScience, 34: 492-498.

Holland, H.D., 1978. The Chemistry of the Atmosphere and Oceans. Wiley, New York, $351 \mathrm{pp}$.

Houghton, R.A., 1986. Estimating changes in the carbon content of terrestrial ecosystems from historical data. In: J.R. Trabalka and D.E. Reichle (Editors), The Changing Carbon Cycle: A Global Analysis. Springer, New York, pp. 173-193.

Houghton, R.A., 1987. Biotic changes consistent with the increased seasonal amplitude of atmospheric $\mathrm{CO}_{2}$ concentrations. J. Geophys. Res., 92: 4223-4230.

Houghton, R.A. and Woodwell, G.M., 1989. Global climatic change. Sci. Am., 260 (4): 36-44 [April.]

Houghton, R.A., Hobbie, J.E., Melillo, J.M., Moore, B., Peterson, B.J., Shaver G.R. and Woodwell, G.M., 1983. Changes in the carbon content of terrestrial biota and soils between 1860 and 1980: A net release of $\mathrm{CO}_{2}$ to the atmosphere. Ecol. Monogr., 53: 235-262.

Kasting, J.F., Richardson, S.M.. Pollack, J.B. and Toon, O.B., 1986. A hybrid model of the $\mathrm{CO}_{2}$ geochemical cycle and its application to large impact events. Am. J. Sci., 286: 361-389.

Keeling, C.D. and Bacastrow, R.B., 1977. Impact of industrial gases on climate. In: Energy and Climate: Studies in Geophysics. National Academy of Sci., Washington, D.C., pp. 72-95. 
Keeling, C.D., Bacastrow, R.B., Carter, A.F., Piper, S.C., Whorf, T.P., Heimann, M., Mook, W.G. and Roeloffzen, $\mathrm{H}$, 1989a. A three-dimensional model of atmospheric $\mathrm{CO}_{2}$ transport based on observed winds. 1. Analysis of observational data. In: D.H. Peterson (Editor), Aspects of Climate Variability in the Pacific and the Western Americas. Am. Geophys. Union, Washington, D.C., pp. 165-236.

Keeling, C.D., Piper, S.C. and Heimann, M., 1989b. A threedimensional model of atmospheric $\mathrm{CO}_{2}$ transport based on observed winds. 4. Mean annual gradients and interannual variations. In: D.H. Peterson (Editor), Aspects of Climate Variability in the Pacific and the Western Americas. Am. Geophys. Union, Washington, D.C., pp. 305-363.

Lasaga, A.C., Berner, R.A. and Garrels, R.M., 1985. An improved model of atmospheric $\mathrm{CO}_{2}$ fluctuations of the past 100 million years. In: E.T. Sundquist and W.S. Broecker (Editors), The Carbon Cycle and Atmospheric $\mathrm{CO}_{2}$ : Natural Variations Archean to Present. Am. Geophys. Union, Washington, D.C., pp. 397-411.

Marshall, H.G., Walker, J.C.G. and Kuhn, W.R., 1988. Longterm climate change and the geochemical cycle of carbon. J. Geophys. Res., 93: 791-802.

Menard, H.W. and Smith. S.M., 1966. Hypsometry of ocean basin provinces. J. Geophys. Res., 71: 4305-4325.

Mook, W.G., Bommerson, J.C. and Staverman, W.H., 1974. Carbon isotope fractionation between dissolved bicarbonate and gaseous carbon dioxide. Earth Planet. Sci. Lett., 22: $169-176$

Neftel, A., Moor, E., Oeschger, H. and Stauffer, B., 1985. Evidence from polar ice cores for the increase in atmospheric $\mathrm{CO}_{2}$ in the past two centuries. Nature, 315: 45-47.

O'Brien, K., 1979. Secular variations in the production of cosmogenic isotopes in the Earth's atmosphere. J. Geophys. Res., 78: 423-431.

Post, W.M., Peng, T.-H., Emanuel, W.R., King, A.W., Dale, V.H. and DeAngelis, D.L., 1990. The global carbon cycle. Am. Sci., 78: 310-326.

Ramanathan, V., Cess, R.D., Harrison, E.F., Minnis, P. and Barkstrom, B.R., 1989. Cloud-radiative forcing and climate: Results from the Earth Radiation Budget Experiment. Science, 243: 57-63.

Revelle, R. and Munk, W., 1977. The carbon dioxide cycle and the biosphere. In: Energy and Climate: Studies in Geophysics. National Academy of Sci., Washington, D.C., pp. $140-158$.

Rotty, R.M. and Marland, G., 1986. Fossil fuel combustion: Recent amounts, patterns, and trends of $\mathrm{CO}_{2}$. In: J.R. Trabalka and D.E. Reichle (Editors), The Changing Carbon Cycle: A Global Analysis. Springer, New York, pp. 474-490.
Schlesinger, W.H., 1986. Changes in soil carbon storage and associated properties with disturbance and recovery. In: J.R. Trabalka and D.E. Reichle (Editors), The Changing Carbon Cycle: A Global Analysis, Springer, New York, pp. 194-220.

Siegenthaler, U. and Munnich, K.O., $1981 .{ }^{13} \mathrm{C} /{ }^{12} \mathrm{C}$ fractionation during $\mathrm{CO}_{2}$ transfer from air to sea. In: B. Bolin (Editor), Carbon Cycle Modelling, SCOPE 16. Wiley, New York, pp. 249-257.

Stuiver, M., 1982. The history of the atmosphere as recorded by carbon isotopes. In: E.D. Goldberg (Editor) Atmospheric Chemistry. Springer, Berlin, pp. 159-179.

Stuiver, M., 1986. Ancient carbon cycle changes derived from tree-ring ${ }^{13} \mathrm{C}$ and ${ }^{14} \mathrm{C}$. In: J.R. Trabalka and D.E. Reichle (Editors), The Changing Carbon Cycle: A Global Analysis. Springer, New York, pp. 109-124.

Stuiver, M. and Quay, P.D., 1980. Changes in atmospheric carbon- 14 attributed to a variable sun. Science, 207 . 11-19.

Sundquist, E.T., 1986. Geologic analogs: Their value and limitations in carbon dioxide research. In: J.R. Trabalka, J.A. Edmonds, J.M. Reilly, R.H. Gardner and D.E. Reichle (Editors), The Changing Carbon Cycle: A Global Analysis. Springer, New York, pp. 371-402.

Tans, P.P., Fung, I.Y. and Takahashi, T., 1990. Observational constraints on the global atmospheric $\mathrm{CO}_{2}$ budget. Science, 247: 1431-1438.

Van der Merwe, N.J., 1982. Carbon isotopes, photosynthesis, and archaeology. Am. Sci., 70: 596-606.

Volk, T., 1987. Feedbacks between weathering and atmospheric $\mathrm{CO}_{2}$ over the last 100 million years. Am. J. Sci., 287: 763-779.

Volk, T., 1989a. Effect of the equatorial Pacific upwelling on atmospheric $\mathrm{CO}_{2}$ during the 1982-1983 El Nino. Global Biogeochem. Cyc., 3: 267-279.

Volk, T., 1989b. Rise of angiosperms as a factor in long-term climatic cooling. Geology, 17: 107-110.

Walker, J.C.G., Hays, P.B. and Kasting, J.F., 1981. A negative feedback mechanism for the long-term stabilization of Earth's surface temperature. J. Geophys. Res., 86: 97769782.

Wilkinson, B.H. and Walker, J.C.G., 1989. Phanerozoic cycling of sedimentary carbonate. Am. J. Sci., 289: 525-548.

Woodwell, G.M., Hobbie, J.E., Houghton, R.A., Melillo, J.M., Moore, B., Peterson, B.J. and Shaver, G.R., 1983. Global deforestation: Contribution to atmospheric carbon dioxide. Science, 222: 1081-1086. 